\title{
Thyroid Hormones and Cancer: A Comprehensive Review of Preclinical and Clinical Studies
}

\author{
Eilon Krashin ${ }^{1,2 \dagger}$, Agnieszka Piekiełko-Witkowska ${ }^{3+}$, Martin Ellis ${ }^{1,4,5}$ and \\ Osnat Ashur-Fabian ${ }^{1,2 *}$
}

${ }^{1}$ Translational Hemato-Oncology Laboratory, Meir Medical Center, Kfar-Saba, Israel, ${ }^{2}$ Department of Human Molecular Genetics and Biochemistry, Sackler Faculty of Medicine, Tel Aviv University, Tel Aviv, Israel, ${ }^{3}$ Department of Biochemistry and Molecular Biology, Centre of Postgraduate Medical Education, Warsaw, Poland, ${ }^{4}$ Meir Medical Center, Hematology Institute and Blood Bank, Kfar-Saba, Israel, ${ }^{5}$ Sackler School of Medicine, Tel Aviv University, Tel Aviv, Israel

\section{OPEN ACCESS}

Edited by:

Veronica Vella,

Università degli Studi di Catania, Italy

Reviewed by:

Elisabetta Ferretti,

Sapienza Università di Roma, Italy

Rocco Bruno,

ASM Matera, Italy Alessandro Antonelli,

University of Pisa, Italy Silvia Martina Ferrari,

University of Pisa, Italy

*Correspondence: Osnat Ashur-Fabian osnataf@gmail.com

†These authors have contributed equally to this work

Specialty section:

This article was submitted to

Cancer Endocrinology,

a section of the journal

Frontiers in Endocrinology

Received: 03 December 2018 Accepted: 22 January 2019

Published: 13 February 2019

Citation:

Krashin E, Piekietko-Witkowska A Ellis M and Ashur-Fabian O (2019) Thyroid Hormones and Cancer: $A$ Comprehensive Review of Preclinical and Clinical Studies

Front. Endocrinol. 10:59. doi: 10.3389/fendo.2019.00059
Thyroid hormones take major part in normal growth, development and metabolism. Over a century of research has supported a relationship between thyroid hormones and the pathophysiology of various cancer types. In vitro studies as well as research in animal models demonstrated an effect of the thyroid hormones T3 and T4 on cancer proliferation, apoptosis, invasiveness and angiogenesis. Thyroid hormones mediate their effects on the cancer cell through several non-genomic pathways including activation of the plasma membrane receptor integrin $\alpha v \beta 3$. Furthermore, cancer development and progression are affected by dysregulation of local bioavailability of thyroid hormones. Case-control and population-based studies provide conflicting results regarding the association between thyroid hormones and cancer. However, a large body of evidence suggests that subclinical and clinical hyperthyroidism increase the risk of several solid malignancies while hypothyroidism may reduce aggressiveness or delay the onset of cancer. Additional support is provided from studies in which dysregulation of the thyroid hormone axis secondary to cancer treatment or thyroid hormone supplementation was shown to affect cancer outcomes. Recent preclinical and clinical studies in various cancer types have further shown promising outcomes following chemical reduction of thyroid hormones or inhibition or their binding to the integrin receptor. This review provides a comprehensive overview of the preclinical and clinical research conducted so far.

\section{Keywords: cancer, thyroid hormone, triiodothyronine, thyroxine, $\alpha \mathrm{v} \beta 3$ integrin}

\section{INTRODUCTION}

Thyroid hormones $(\mathrm{TH})$ are key regulators of essential cellular processes including proliferation, differentiation, apoptosis, and metabolism. Hypothalamic thyrotropin-releasing hormone (TRH), activates the pituitary gland to synthesize and secret thyroid stimulating hormone (TSH), which in turn acts at the thyroid gland to stimulate TH synthesis and secretion (1). Tetraiodothyronine (T4), the main hormone synthesized in the thyroid gland, is catalyzed to the Triiodothyronine (T3) by specific iodothyronine deiodinases (2). T3 acts as the principal TH mediating metabolic activity, via formation of complexes between T3 and nuclear thyroid hormone receptors alpha (TR $\alpha$ ) and beta (TR $\beta)$. This nuclear T3-receptor complex binds to thyroid hormone response elements on specific genes, regulating their transcription (3). Diseases associated with excess of TH (hyperthyroidism) and lack of TH (hypothyroidism) are common and present with distinct clinical symptoms. 
More than a century ago the association between thyroid hormones and malignancies was first suggested (4). Later, Hercbergs and Leith (5) hypothesized that TH deficiency may affect cancer outcome. This assumption was supported by numerous clinical studies, demonstrating that hypothyroidism inhibits tumor growth, while hyperthyroidism produces an opposite effect (6). A great deal of research has been conducted in recent decades to determine how thyroid hormones exert their growth-promoting effect (7). These mechanisms are now better understood following the discovery of a non-genomic pathway for $\mathrm{TH}$ action. $\alpha \mathrm{v} \beta 3$ is a plasma membrane integrin which acts as a membrane receptor for TH (3). This receptor was shown to contain two distinct binding sites for the hormones, S1 and S2, each translating unique signaling cascades (8). While the S1 site binds solely physiological levels of T3, leading to PI3K activation, the second site, S2, binds T4, and with a lower affinity, T3, activating the ERK1/2 pathway (9). $\alpha v \beta 3$ integrin binding facilitates the hormones proliferative action on cancer cells as well as blood vessel cells (3).

In this review, we will provide a summary of studies which examined the link between thyroid hormones and cancer. We will first present the preclinical research on the effects of $\mathrm{TH}$ in various cancer models, both in vitro and in vivo. We will then outline clinical studies examining various aspects of this association including the effect on cancer risk, behavior and outcome.

\section{IN VITRO STUDIES OF THE THYROID-CANCER ASSOCIATION}

This section summarizes the in vitro studies on thyroid hormonecancer association, presented in Table 1. A comprehensive list of the in vitro studies, including cancer cell lines and thyroid hormone concentrations, is presented in Supplemental Table 1.

\section{Breast Cancer Cell Models}

In vitro, thyroid hormones were shown to induce proliferation of breast cancer cells $(10,11,14)$. These growth promoting effects were comparable to that of estrogen (E2) and the proliferative effects of $\mathrm{T} 3$ or $\mathrm{T} 4$ were blocked by co-administration of an estrogen receptor (ER) antagonist, suggesting a significant crosstalk between the two hormones $(11,12,14)$. T3 is able to activate estrogen response elements-mediated gene expression in cancer cells (11). In addition, T3 induces the mRNA expression of the growth factors TGF $\alpha$ and TGF $\beta$ in ER positive breast cancer cells, while the ER modulator tamoxifen reverts this effect $(13,101)$. T3 treatment of ER positive ductal carcinoma cells leads to an increase in P53 and Rb phosphorylation, while an ER antagonist blocks these effects (12). T4 induces serine phosphorylation of $E R \alpha$, which leads to DNA binding and transcriptional activation by the receptor (14). $\mathrm{TH}$ also demonstrates tumor promoting effects irrespective of ER signaling. In aggressive triple negative breast cancer cells, T3 enhances aerobic glycolysis (Warburg effect), a hallmark of transformed cells (22). Via a rapid signaling pathway mediated by the integrin $\alpha v \beta 3$, T3 was also shown to regulate actin remodeling and to stimulate breast cancer cell migration and invasion (15). T4 was recently shown to stimulate PD-L1 gene expression and increase PD-L1 protein through activation of ERK1/2, thereby supporting the activity of this defensive checkpoint against immune destruction in breast cancer cells (16). In ER negative breast cancer cells, the $\alpha v \beta 3$ inhibitor tetraiodothyroacetic acid (tetrac) hinders thyroid hormone cellular actions initiated via the membrane receptor. Nanoparticulate tetrac induces apoptosis through downregulation of apoptosis inhibitors such as XIAP and MCL1 and upregulation of apoptosis promotors such as CASP2 and BCL2L14. Nanotetrac also increases the expression of angiogenesis inhibitor THBS1 as well as the expression of CBY1, a catenin activity inhibitor, and attenuates Ras-oncogene family members (17). It also reduces the effect of T4 on PDL1 gene and protein expression (16). This further supports the assumption that the growth promoting effects of thyroid hormones in breast cancer are mainly mediated through the membrane receptor $\alpha v \beta 3$.

\section{Prostate Cancer Cell Models}

Thyroid hormones have shown disparate effects in prostate cancer cells, depending on the thyroid hormone involved (T3 or T4) and cell line investigated. The proliferation of androgen-dependent, but not androgen-independent prostate cancer cells was enhanced by T3. In androgen-dependent cell lines T3 downregulated the expression of the anti-proliferative protein, BTG2 (34). In low invasive prostate cancer cells, but not in highly invasive cancer cells, T4 induced the acquisition of neuroendocrine-like morphology, VEGF secretion and invasive capacity (35). In these cells, while T3 itself had no effect, isoproterenol-stimulated neuroendocrine-like morphology and invasiveness were prevented in the presence of T3. In another study, migration was enhanced and detachmentinduced apoptosis was inhibited by $\mathrm{T} 4$ in prostate cancer cells, while tetrac, the $\alpha v \beta 3$ inhibitor, reversed these effects through diminished activity of the MAPK pathway and inhibited expressions of XIAP, MMP2 and VEGF, suggesting involvement of the integrin in these effects (36).

\section{Lung Cancer Cell Models}

$\mathrm{T} 4$ at physiologic concentrations and T3 at supraphysiologic concentrations increase abundance of proliferating cell nuclear antigen (PCNA) and ERK1/2 activation, markers of cell proliferation, in small cell and non-small cells lung cancer models (39). Interestingly, thyroid hormones led to phosphorylation of $\mathrm{ER} \alpha$, while an ER $\alpha$ antagonist blocked T4 induced PCNA expression, ERK1/2 activation and $\mathrm{ER} \alpha$ phosphorylation. This suggests, as demonstrated in breast cancer cells, that thyroid hormone mitogenic effects mediated via the plasma membrane may involve an ER $\alpha$ dependent pathway. Tetrac, as well as pharmacologic inhibition of the MAPK pathway, blocked lung cancer cell proliferation in response to thyroid hormones (39, 40). Moreover, in human non-small cell lung cancer cells, T4 at physiological concentrations enhanced internalization and nuclear translocation of the integrin $\alpha \mathrm{v}$ monomer. $\alpha \mathrm{v}$ monomer then binds inside the cell nucleus promoters of central cancer-related genes, such as ER $\alpha$, cyclooxygenase-2, 
TABLE 1 | Preclinical studies on thyroid hormones and cancer.

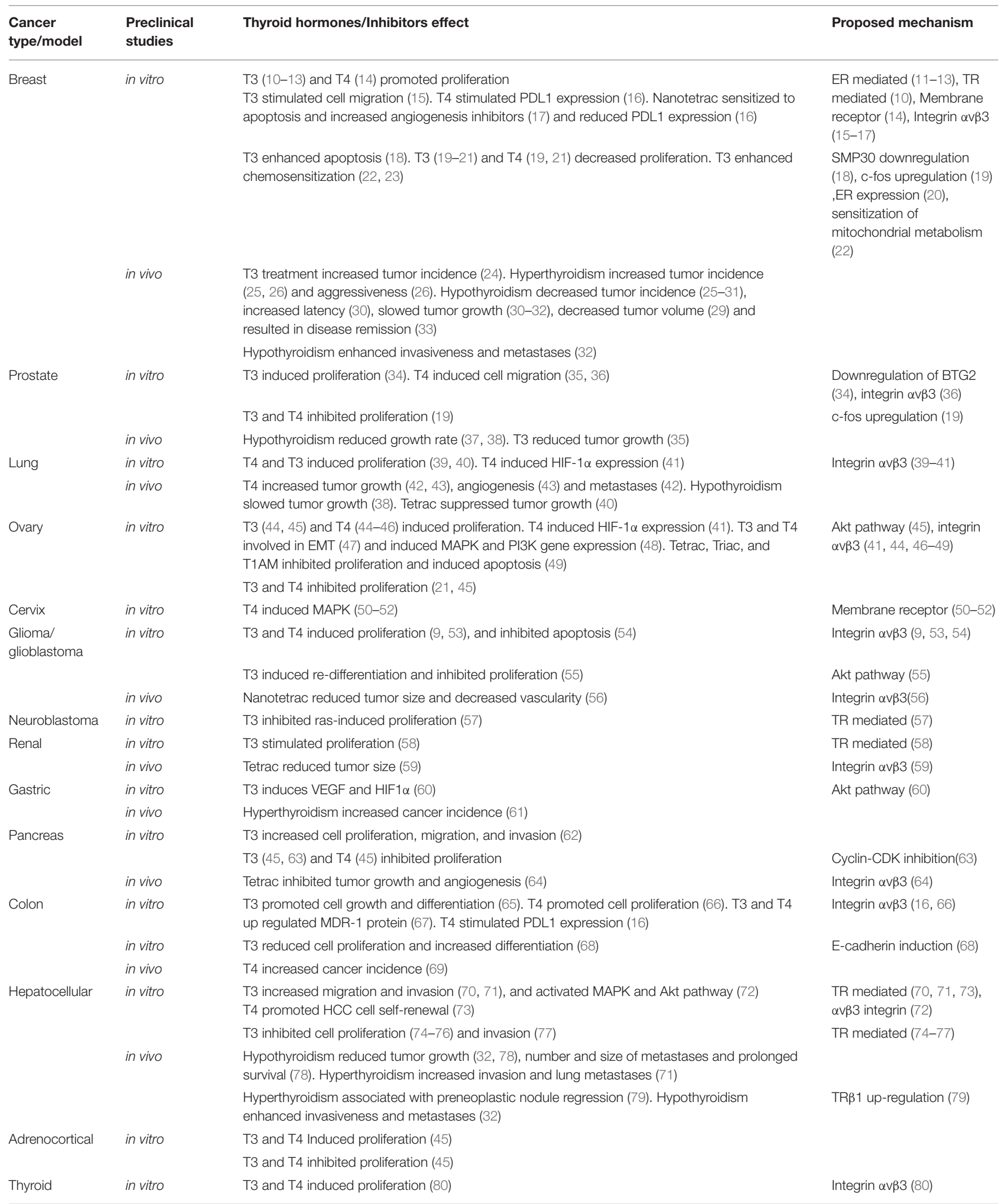


TABLE 1 | Continued

\begin{tabular}{|c|c|c|c|}
\hline $\begin{array}{l}\text { Cancer } \\
\text { type/model }\end{array}$ & $\begin{array}{l}\text { Preclinical } \\
\text { studies }\end{array}$ & Thyroid hormones/Inhibitors effect & Proposed mechanism \\
\hline & in vivo & Hypothyroidism reduced tumor growth (81). Tetrac inhibited tumor growth $(82,83)$ & Integrin $\alpha \vee \beta 3(82,83)$ \\
\hline Melanoma & in vivo & Hypothyroidism increased tumor latency and survival (84) & \\
\hline \multirow{2}{*}{$\begin{array}{l}\text { Basal cell } \\
\text { carcinoma }\end{array}$} & in vitro & T3 reduced growth and induced apoptosis (85) & PKA induction (85) \\
\hline & in vivo & T3 reduced tumor growth (85) & \\
\hline Ehrlich tumor & in vivo & Hyperthyroidism increased tumor size (86) and ascitic volume (87) & \\
\hline Sarcoma & in vivo & Hyperthyroidism increased tumor size and metastases (88) & \\
\hline \multirow[t]{2}{*}{$\begin{array}{l}\text { Multiple } \\
\text { myeloma }\end{array}$} & in vitro & $\begin{array}{l}\text { T3 and T4 induced proliferation and viability }(89,90) \text { and increase cell migration and invasion } \\
\text { (91) }\end{array}$ & Integrin $\alpha v \beta 3$ (89-91) \\
\hline & in vitro & Tetrac inhibited proliferation and induced apoptosis (92) & Integrin $\alpha \vee \beta 3$ (92) \\
\hline Leukemia & in vitro & No direct effect of T3 and T4 (93) & \\
\hline \multirow[t]{2}{*}{ Lymphoma } & in vitro & T3 and T4 induced proliferation and VEGF expression (94) & Integrin $\alpha \vee \beta 3$ (94) \\
\hline & in vivo & Hyperthyroidism increased tumor growth $(95,96)$ and reduced survival $(96)$ & \\
\hline Angiogenesis & $\begin{array}{l}\text { ex vivo (CAM } \\
\text { model) }\end{array}$ & $\begin{array}{l}\text { T3 }(97,98) \text { and T4 }(97-100) \text { induced angiogenesis. Tetrac arrested tumor related angiogenesis } \\
(40,59,82,83)\end{array}$ & $\begin{array}{l}\text { Membrane receptor (98), } \\
\text { integrin } \alpha \vee \beta 3 \\
(40,59,82,83,97,99,100)\end{array}$ \\
\hline
\end{tabular}

hypoxia-inducible factor- $1 \alpha$ (HIF $1 \alpha)$, and thyroid hormone receptor $\beta 1$ (41).

\section{Gynecological Cancer Cell Models}

In ovarian cancer cells T3 at supra physiological and T4 at physiological concentrations induced cell proliferation, survival and viability and led to $\alpha v \beta 3$ mediated ERK up-regulation $(44,46)$. Genes that constrain cell cycle (p21, p16), promote mitochondrial apoptosis (Nix, PUMA), and tumor suppression (GDF-15, IGFBP-6) were inhibited by TH, while a hypothyroid environment attenuated ovarian cancer growth (44). TH were also shown to be involved in $\alpha v \beta 3$ mediated epithelial to mesenchymal (EMT) transition in ovarian cancer cells, inducing mesenchymal markers zeb-1, slug, and vimentin, and inhibiting the epithelial markers, e-cadherin and zo-1 (47). This suggests a possible implication for $\mathrm{TH}$ in ovarian cancer metastases. The $\alpha v \beta 3$ inhibitor tetrac induced ovarian cell apoptosis as well as upregulation of ATM and PARP-1, proteins that coordinate recognition of DNA damage (49). As demonstrated for lung cancer models, $\alpha \mathrm{v}$ monomer internalization and nuclear translocation were induced by $\mathrm{T} 4$, activating multiple genes involved in cancer promotion (41). Importantly, and comparable with results from breast cancer, crosstalk between integrin $\alpha v \beta 3$ and $E R \alpha$ promoted the proliferation of ovarian cancer cells by $\mathrm{TH}$, mimicking functions of E2. Both T4 and E2 promoted nuclear translocation of the integrin $\alpha \mathrm{v}$ monomer as well as the phosphorylation of $\mathrm{ER} \alpha$, while the presence of an antagonist for ER $\alpha$ blocked T4-induced ERK1/2 activation, ER $\alpha$ phosphorylation, PCNA expression and cell proliferation (46).

In cervical cancer cells (HeLa), T4 was demonstrated to rapidly induce phosphorylation and nuclear translocation of MAPK (50) and to potentiate EGF and TGF $\alpha$-induced MAPK activation (51). These effects could not be mediated through TR, as HeLa cells lack these receptors. These effects were reproduced by $\mathrm{T} 4$-agarose and blocked by tetrac, suggesting a membrane receptor involvement (50-52).

\section{Central Nervous System Tumor Cell Models}

In glioma cells T4 caused proliferation and upregulation of PCNA and MAPK. This effect was inhibited by tetrac, suggesting mediation by the $\alpha v \beta 3$ integrin (53). In another study in glioma cells, T3 and T4, acting on the $\alpha v \beta 3$ integrin, induced proliferation and activation of ERK1/2, while only T3 activated Src kinase and its downstream PI3-kinase signaling cascade. These findings suggested that the integrin contains two iodothyronine receptor domains, activating different pathways (9). Resveratrol-induced-apoptosis was inhibited in glioblastoma cells by T4, through interference with nuclear COX-2 and ERK1/2 interaction. This effect was prevented by tetrac (54). Other studies demonstrated conflicting results. In both astrocytoma and glioblastoma cells, T3 promoted re-differentiation. T3 increased cell proliferation and phosphoAkt levels in astrocytoma cells, yet suppressed cell proliferation in glioblastoma cells, suggesting differing effects related to cancer aggressiveness (55). In neuroblastoma cells, T3 inhibited ras-induced proliferation and blocked induction of cyclin D1 expression by the oncogene (57). T3 strongly antagonized the transcriptional response mediated by the Ras/MAPK signaling pathway in neuroblastoma cells expressing TRs.

\section{Renal Cancer Cell Models}

Renal cancer is associated with multiple aberrances of thyroid hormone signaling pathway. These include mutations and altered expression of thyroid hormone receptors, decreased intratumoral concentrations of T3, as well lowered expression and disturbed alternative splicing of type 1 iodothyronine deiodinase (102106). In contrast to normal kidney cells, which decrease proliferation in response to $\mathrm{T} 3$, divisions of renal cancer cell 
lines are stimulated by $\mathrm{TH}$ (58). These different $\mathrm{T} 3$ effects are the result of distinct, cell type specific regulation of genes that control cell cycle progression. In renal cancer cells T3 attenuates expressions of E2F4, p107, and p130, while in healthy kidney cells the expression of p107 is stimulated by T3. p107 and p130 are proteins of the retinoblastoma family which enable binding of E2F4 and E2F5 to form CERC (cyclin E repressor complex). During G1 phase, CERC interacts with and negatively affects the activity of promoter of CCNE1, encoding cyclin E1, thus repressing proliferation (107). In consequence of these disparate effects on gene expression, T3 accelerates cell cycle progression in renal cancer cells, triggering progression to $S$ phase. In contrast, in normal kidney cells, cell cycle progression is attenuated by T3 (58). These pro-proliferative T3 effects on renal cancer cells were confirmed by an independent study (108).

\section{Gastrointestinal Cancers Cell Models}

$\mathrm{T} 4$ and T3 differently influence gastrointestinal cancer cells. In contrast to renal tumors, gastric cancers accumulate T3, possibly due to overexpressed transthyretin that mediates cellular T3 import (60). The increased intracellular T3 concentration directly contributes to cancer progression, by inducing the expression of HIF1 $\alpha$, which in turn activates the expression of proangiogenic VEGF. Interestingly, these T3 effects are mediated by accumulation of fumarate, one of the key intermediates of TCA cycle, acting as an inhibitor of HIF1 $\alpha$ degradation. These T3 effects are mediated by rapid non-genomic mechanisms, involving PI3K signaling (60). T4, acting on $\alpha v \beta 3$ receptors, stimulates colon cancer cell proliferation and activation of PCNA, cyclin D1, and c-Myc (66). These pro-cancerous T4 effects can be prevented by tetrac and nanotetrac. Furthermore, tetrac and nanotetrac potentiate antiproliferative activity of cetuximab, an anti-EGFR antibody, suggesting potential beneficiary effects of these drug combinations in colon cancer patients (66). These pro-mitogenic effects of extracellular T4 are in sharp contrast to mechanisms initiated by T3. Dentice et al. showed that treatment of colon cancer cells with T3 induces their differentiation with concomitant reduced proliferation (68). T3 activated tumor-suppressive E-cadherin, triggering plasmamembrane localization of beta-catenin, thus preventing its nuclear mitogenic activity. These protective T3 actions are prevented by activated beta-catenin which stimulates expression of type 3 deiodinase and downregulates type 2 deiodinase, thereby reducing intracellular T3 pool. In colon cancer cells, T4 mediated the activation of MDR1, suggesting that thyroid hormones may promote drug resistance mechanisms $(67,109)$.

The effects of T3 in pancreatic tumor cells depend on tumor type. Proliferation of some, but not all, cell lines derived from highly aggressive pancreatic adenocarcinoma was suppressed by T3 (63). Mechanistically, T3 changed expressions of cell cycle regulators, leading to downregulation of cyclins D1 and E, and upregulation of cdk inhibitors, p21 $1^{\text {cip1 }}$ and p27 kip1. Furthermore, T3 attenuated the activity of cyclin-CDK complexes, which resulted in reduced $\mathrm{pRb}$ phosphorylation and G1 cell cycle arrest. In contrast, the proliferation, migration, and invasion of pancreatic cancer cells was stimulated by T3 in vitro (62). These results fit observations of patients in which hypothyroidism treated with $\mathrm{TH}$ supplementation correlated with increased risk of tumor progression and poor prognosis (62). Thyroid hormones were shown to potentiate cytotoxic effects of chemotherapeutics in pancreatic cancer cells (63).

Conflicting in vitro results exist regarding the effect of thyroid hormones in hepatocellular carcinoma (HCC). Several studies demonstrated that T3, acting on the TR, leads to inhibition of cancer cell growth. In HCC cells, T3 downregulated oncogenes $\mathrm{CDK} 2$, cyclin $\mathrm{E}$ and phospho-Rb (74) and up regulated the tumor suppressor p21 and endoglin $(74,75)$. T3 also induced DKK4, which suppresses cell invasion and metastatic potential via reduction of matrix MMP2 (77) and downregulated ELF2, a transcription factor associated with tumor growth and cell proliferation (76). In vitro experiment confirmed that TR $\beta 1$ silencing enhanced proliferation and migration of human HCC cells (79). Conversely, T3 action on TR may increase HCC aggressiveness. A high frequency of somatic point mutations of $\operatorname{TR} \alpha$ and $\operatorname{TR} \beta$ were identified in human HCC samples $(110,111)$. T3 was associated with increased HCC invasiveness through up regulation of furin (70) and lipocalin 2 (71) in a TR dependent manner. Lipocalin 2 and TR $\alpha$ were both overexpressed in HCC patient samples and correlated with cancer grade, stage, and survival (71). T4 action on TR $\alpha$ promoted HCC cells selfrenewal, increased cancer stem-like cells and drug resistance and upregulated NF-kB (73). Finally, T3 binding to integrin $\alpha v \beta 3$ in HCC cells, induced growth-promoting effects via ERK1/2 and Akt phosphorylation (72).

\section{Hematological Malignancies Cell Models}

T4 and T3 stimulate proliferation and viability of multiple myeloma (MM) cells by activating $\alpha \mathrm{v} \beta 3$ integrin receptor, leading to rapid activation of the MAPK signaling pathway $(89,90)$. This in turn, results in activation of genes involved in proliferation (PCNA), and reduced expression of genes encoding apoptotic regulators such as apafl, caspase-3, puma, and noxa (90). Remarkably, the integrin-mediated $\mathrm{TH}$ actions may contribute to progression of MM by changes in adhesion and remodeling of extracellular matrix. Specifically, T3 and T4 increased adhesion of MM cells to fibronectin and activated expression of MMP-9 via a mechanism involving $\alpha \mathrm{v} \beta 3$ and MAPK (91). These in vitro results are of potential clinical importance, since tetrac inhibited MM cell proliferation and induced apoptosis. Furthermore, tetrac sensitized patient-derived MM cells to bortezomib, providing a potential new therapeutic option (92). Tetrac also blocked TH-mediated induction of MMP-9 (91).

TH affect proliferation of T-cell lymphoma (TCL) cells by simultaneous induction of genomic and non-genomic mechanisms $(112,113)$. The non-genomic mechanisms involve rapid membrane translocation of $\mathrm{PKC} \zeta$ isoform and activation of ERK and NF- $\mathrm{BB}$. One of the downstream targets of PKC $\zeta$ signaling is inducible nitrix oxide synthase (iNOS), a well-known activator of TLC proliferation. Barreiro Arcos et al. showed that intracellular activity of $\mathrm{TH}$ is prerequisite for activation of iNOS expression, along with enhanced expression of TR $\alpha$ (113). Non-genomic TH actions also contributed to survival and progression of TCL. Specifically, binding of TH to $\alpha v \beta 3$ receptors, triggered pro-proliferative, and proangiogenic signals 
including enhanced expression of cyclins, PCNA, and VEGF. This TH-induced secretion of VEGF stimulated proangiogenic activity of endothelial cells, possibly contributing to TCL progression (94). In another study, in vitro treatment of lymphoma cells with $\mathrm{T} 3$ and $\mathrm{T} 4$ activated proliferation, as indicated by increased expressions of PCNA, as well as cyclins $\mathrm{D}, \mathrm{A} 2$, and $\mathrm{B}(95)$.

\section{In vitro Studies in Other Cancer Models}

The cancers originating from thyroid gland are influenced by its own secretory products. Specifically, T4 and T3 promote proliferation of follicular and papillary thyroid cancers in vitro (80). These effects are largely mediated by non-genomic signaling involving $\alpha v \beta 3$ receptor as indicated by tetrac blockade of the TH-induced proliferation. Furthermore, T4 treatment blocked pro-apoptotic signaling induced by external stimuli such as resveratrol (80). Altogether, this data indicates procancerous and anti-apoptotic role of TH in thyroid cancers. An inhibitory role of $\mathrm{TH}$ was reported for skin cancer. T3 inhibited proliferation and induced apoptosis in basal cell carcinoma cells (85). Mechanistically, T3 reduced protein stability and transcriptional activity of Gli2, an oncogenic transcription factor, that promotes $\mathrm{G} 1 / \mathrm{S}$ cell cycle phase transition.

Moriggi et al. tested TH influence on six cell lines derived from various types of cancer that differed by the profile of mutations in genes involved in PI3K and beta-catenin signaling pathways. Remarkably, for each cancer type, T3 exerted dual effect, either stimulating or attenuating proliferation. Unfortunately, the presented data did not clarify the cause of this differential T3 effects (45). The results of this study underscore the complexity of mechanisms involved in TH-mediated effects in cancer cells.

Taken together, the results of the in vitro studies suggest that effects of thyroid hormones in cancer are mediated by complex genomic and non-genomic signal transduction pathways and are highly dependent on cell type and molecular context. These biological pathways were extensively summarized in a recent review by Goemann et al. (114).

The complex and often contradictory T4 and T3 effects observed in vitro underline the importance of in vivo studies, which can provide valuable information on the net $\mathrm{TH}$ effects in a living organism. On the other hand, in vitro experiments provide a unique opportunity to reveal mechanistic details of intra- and extracellular processes initiated by T4 and T3 in cancer cells. Inevitably, both types of studies are required to clarify the role of $\mathrm{TH}$ in cancer development and progression.

\section{IN VIVO STUDIES OF THE THYROID-CANCER ASSOCIATION}

This section summarizes the in vivo studies on the thyroid hormone-cancer association, presented in Table 1. A comprehensive list of in vivo studies is presented in Supplemental Table 2.

\section{Breast Cancer Animal Models}

One of the earliest reports analyzing in vivo the link between thyroid hormones and breast cancer was published in 1946.
Treatment of mice with the thyroid synthesis inhibitor, thiourea, delayed development of spontaneous breast tumors (115). Similar results were achieved when mice were treated with another compound, thiouracil (116). These results were further validated by Vonderhaar et al., who found that thiouracilinduced hypothyroidism delayed development and decreased incidence of spontaneous breast tumors in mice (27). The study suggested that hypothyroidism could contribute to local atrophy of mammary glands, resulting in reduced tumor formation. Contrasting results were obtained on experimental Ehrlich tumors (ET) that arise from mouse mammary adenocarcinoma (86). In that study, hyperthyroidism decreased metabolic activity and proliferation of ET as evidenced by lowers nuclear diameter, mitotic index, and number of nucleolus organizer regions. TH effects were also tested in vivo in models of chemically induced breast tumors. Early studies brought inconclusive results, showing that both thyroidectomy and thyroxine supplementation reduced incidence of breast tumors (117). However, a series of later reports clearly demonstrated the protective effect of PTU (propylthiouracil)-induced hypothyroidism. PTU given at a dose that produced severe hypothyroidism in rats, dramatically reduced the incidence of 7,12-dimethylbenz(a)anthracene (DMBA) (28) and $\mathrm{N}$ methyl-N-nitrosourea (MNU) (29) induced breast tumors. A more recent study further demonstrated that PTU-induced hypothyroidism delayed development and reduced incidence of DMBA-induced mammary tumors by activating apoptosis (30). The protective effects of hypothyroidism were also shown in a model of breast tumor xenografts. Treatment with PTU inhibited growth of inoculated mammary adenocarcinomas and improved survival of mice (31). Spectacular effects of PTU treatment were reported by Shoemaker and Dagher who demonstrated complete remission of mammary tumor xenografts in $77 \%$ of PTU-treated mice (33). Confounding reports on the influence of thyroidal status in human cancer was partially explained by Martínez-Iglesias et al. (32). Their study revealed that while the growth of breast cancer cells inoculated into hypothyroid hosts was delayed, the tumors were more invasive and metastatic. The tumors grown in hypothyroid animals were more undifferentiated, with reduced expression of epithelial markers (e.g., keratin 8/18, $\beta$-catenin) and enhanced expression of mesenchymal markers (vimentin). However, the same study demonstrated that hypothyroidism reduces cancerous proliferation and stimulates necrosis in tumors, resulting in retarded tumor growth (32). In a parallel study, the same group showed that overexpression of thyroid hormone receptor $\beta(\operatorname{TR} \beta)$ attenuated growth of breast tumor xenografts in mice, indicating its tumor suppressive activity (118). These studies demonstrated that intracellular and extracellular effects of thyroid hormones can differently contribute to development and progression of breast cancer, affecting both cancer cells and tumor stroma.

\section{Prostate Cancer Animal Models}

Consistently with results described above, PTU-induced hypothyroidism attenuated growth of prostate cancer xenografts in athymic mice $(37,38)$. The latter study clearly demonstrated that PTU did not affect the proliferation of prostate cancer 
cells in vitro, supporting the conclusion that anticancer effect was the result of hypothyroid state of the animals (38). In contrast to these suppressive effects of hypothyroidism, a more recent study reported that treatment with T3 $(2.5 \mu \mathrm{g} /$ day $)$ inhibited growth of prostate tumors inoculated in nude mice (35).

\section{Lung Cancer Animal Models}

One of the early in vivo studies on TH effects on lung cancer was performed using a model of Lewis lung carcinoma (3LL), an undifferentiated squamous cell carcinoma that spontaneously developed in the lung of C57/BL6 mouse (42). Hyperthyroidism induced by $\mathrm{T} 4$ administration significantly increased growth of tumors inoculated by subcutaneous injections of 3LL cells in mice. In contrast, hypothyroidism triggered by methimazole treatment attenuated tumor growth and increased survival of the animals. Remarkably, T3 and T4 differently affected progression of the disease. The number of pulmonary metastases was reduced by treatments with $\mathrm{T} 3$ or methimazole while it was increased by treatment with T4. The reduction of tumor growth by methimazole was probably a result of its direct inhibitory effect on cancer cells, since in vitro experiments revealed that methimazole suppressed growth of 3LL cells (42). However, another study showed that hypothyroidism itself can also suppress growth of lung tumors. Treatment with PTU significantly suppressed growth of lung tumors subcutaneously inoculated in mice. This PTU effect was possibly not the result of suppressive effect on cancer cells since in a parallel experiment PTU did not affect growth of prostate cancer cells in vitro (38). Interestingly, it was suggested that $\mathrm{TH}$ may also affect cancer progression by influencing immune response. In the abovementioned study both T4 and methimazole suppressed the activity of NK cells, while alveolar macrophages were activated by $\mathrm{T} 4$ and $\mathrm{T} 3$ (42). This data indicates that $\mathrm{T} 4$ and $\mathrm{T} 3$ have broad effects on lung cancer development and progression, not only via direct effects on cancer cells but also by influencing tumor environment and elements of the immune system. The direct effects of T4 on lung cancer cells are probably the result of non-genomic actions. Interesting data was provided by a large study involving 100 mice with Lewis lung carcinoma tumors in which interactions between thyroid hormone and nitric oxide signaling were analyzed (43). Treatment of mice with T4 resulted in a remarkable increase of tumor weight compared to euthyroid animals. These effects were associated with increased expression of VEGF, suggestive of enhanced vascularization. Furthermore, intraperitoneal injections of tetrac, an antagonist of $\mathrm{T} 4$ binding to integrin $\alpha \mathrm{v} \beta 3$, significantly reduced tumor growth and VEGF expression. These results suggested that pro-tumorous T4 effects in 3LL cells are mediated by $\alpha v \beta 3$ integrin receptor (43). Similar data was obtained in non-small cell lung cancer cells in which pro-proliferative $\mathrm{T} 4$ actions were blocked by antibody directed against integrin $\alpha v \beta 3$ as well as by tetrac (40). These promising therapeutic effects of tetrac were also confirmed in studies involving other tumors $(56,64,82)$.

\section{In vivo Studies of Gastrointestinal Cancers}

Several lines of evidence indicate that high T4 levels promote gastrointestinal carcinogenesis in vivo. In rats, T4 administration increased incidence of chemically induced tumors of colon and stomach $(61,69)$. TH effects were comprehensively analyzed in models of liver neoplasia. It was shown that hypothyroidism delays progression of experimental Morris hepatoma tumors implanted in female Buffalo Rats (78). Specifically, hypothyroidism induced within 2 weeks from tumor implantation not only attenuated growth of localized tumors but also decreased the number of lung metastases and prolonged survival of the animals. These results were further supported by later studies demonstrating tumor suppressive role of TR $\beta 1$ in the progress of hepatocellular carcinoma (HCC). Using rat model of HCC, Frau et al. (79) showed that expressions of $\operatorname{TR} \alpha 1$ and TR $\beta 1$, along with downregulated expressions of their targets, are decreased in tumors. Notably, downregulation of TR $\beta 1$ expression was associated with high proliferative activity of liver cells. TR $\beta 1$ expression was also decreased in human HCC tissue samples. In contrast, induction of hyperthyroidism in rats bearing nodules resulted in increased $\operatorname{TR} \beta 1$ expression and regression of preneoplastic lesions. These results clearly suggest a tumor suppressive role of TR $\beta 1$ in HCC. However, contrasting results were published on the role of $\mathrm{TR} \alpha 1$ in HCC (71), showing that TR $\alpha 1$ is overexpressed in human HCC and stimulates migration and invasion in vitro and in vivo. Under hyperthyroid conditions HCC cells expressing TR $\alpha 1$ induced invasion and metastases formation in mice. These effects were mediated via MET/FAK pathways. These results were further confirmed by analysis of human HCC tissue samples in which high expressions of TR $\alpha 1$ were associated with lower patients' survival. Remarkably, no such correlation was observed for TR $\beta 1$. The authors suggested that T3/TR could play a dual, oncogenic or tumor suppressive role, depending on the molecular background and stage of the disease. So far, this hypothesis was not supported by experimental data. Curiously, the same research group published contrasting results on the expression of TRs in human HCC tissue samples. In a study published in 2012 they reported decreased expressions of TRs (including TR $\alpha 1$ ) in HCC specimens and concluded that TRs play a tumor suppressive role (119). Clearly, the role of T3 and TRs in HCC requires further elucidation in independent studies involving both human tissue samples and in vivo experiments in mice.

\section{In vivo Studies of Hematological Malignancies}

The earliest in vivo studies exploring the relations between $\mathrm{TH}$ and leukemia brought inconsistent results. One study reported decreased incidence of spontaneous lymphatic leukemia in mice with T4-induced hyperthyroidism when compared with hypothyroid mice treated with PTU (120). The hypo- and hyperthyroid leukemic animals did not differ in their survival rates. However, interpretation of these results is challenging, mainly due to limited information on methods and criteria used for leukemia diagnosis in the animals. In contrast, Morris 
et al. showed that PTU-induced hypothyroidism attenuated lymphomatous infiltrations in rats compared with euthyroid animals (121). Furthermore, hypothyroidism prolonged survival of mice and rats with transplanted lymphomas, while T4 treatment of euthyroid animals resulted in the opposite effects. Different results were obtained in a study focused on progression of acute stem-cell leukemia in rats. The animals were rendered hypothyroid by several methods, including thyroidectomy and thyroid gland ablation with radioactive iodine. Apparently, none of these treatments influenced growth of subcutaneously inoculated tumors nor affected survival of the animals (122).

Non-genomic TH effects were reported for T-cell lymphomas (TCL), defined as a group of heterogeneous lymphoproliferative disorders. TH stimulated TCL proliferation and angiogenesis by acting through $\alpha \mathrm{v} \beta 3$ integrin receptor (94). TH binding to $\alpha \mathrm{v} \beta 3$ triggered activation of VEGF and NF- $\kappa \mathrm{B}$ pathways, resulting in stimulation of angiogenesis and proliferation. This study further showed that selective inhibition of $\alpha v \beta 3$ with cilengitide attenuates growth of TCL xenografts in mice. An interesting study providing the link between $\mathrm{TH}$, stress, and cancer was published by Frick et al. (93). They showed that chronic stress led to suppression of $\mathrm{TH}$ plasma levels which was associated with attenuation of T-cell proliferation in response to mitogens, suggestive of impaired immune functions. Supplementation with T4 protected T-cells against stress-induced suppression of proliferation. More importantly, treatment with T4 prevented stress-induced growth of lymphoma tumors subcutaneously inoculated in mice. The study also suggested that $\mathrm{TH}$ antitumor effects could be mediated by PKC isoforms $\theta$ and $\alpha$. Exposition of the animals to stress diminished activation of these PKC isoforms. In contrast, T4 supplementation counteracted stressinduced attenuation of PKC activation.

Thyroid hormone status can have dual effect on lymphoma growth and metastasis as shown by a study in which hyperthyroidism stimulated local tumor growth while hypothyroidism fostered formation of metastatic lesions in kidneys (95). Interestingly, these dual effects of $\mathrm{TH}$ on primary and secondary malignancies seem to be a more generalized mechanism since similar observations were made in the above mentioned mouse model of breast cancer. Lymphoma cells inoculated in hyperthyroid animals grew faster, with enhanced tumoral and peritumoral vasculogenesis, and increased expression of PCNA and caspase 3 (96). These effects were associated with shorter survival of hyperthyroid animals when compared with eu- and hypothyroid mice. Similar to the effects described in vitro (95), enhanced expressions of PCNA and cyclins D and E was described in tumors grown in hyperthyroid animals, when compared with eu- and hypothyroid animals. Surprisingly, hyperthyroidism stimulated apoptosis, as demonstrated by activation of caspase 3 and Bax. The enhanced metastasis observed in hypothyroid animals could be the effect of changes in immune responses. Hypothyroidism increased the percentage of $\mathrm{CD} 4^{+} \mathrm{CD} 25^{+}$FoxP3 ${ }^{+}$Treg cells in tumor draining lymph nodes (TDLN). Tregs suppress activation and proliferation of $\mathrm{CD} 4+$ and $\mathrm{CD} 8+\mathrm{T}$ lymphocytes. Likewise, activated $\mathrm{CD}^{+} \mathrm{T}$ cells $\left(\mathrm{CD} 8^{+} \mathrm{CD}^{+} 9^{+}\right.$or $\left.\mathrm{CD} 8^{+} \mathrm{CD} 44^{\mathrm{hi}}\right)$ were decreased in TDLN of hypothyroid animals. The presence of immunosuppressive Tregs in hypothyroid TLDN possibly contributed to metastatic progression, since depletion of CD8+ cells resulted in enhanced metastasis in mice (95). In contrast, $\mathrm{TH}$ could prevent metastasis by activation of apoptosis. Indeed, tumors grown in hyperthyroid animals showed increased presence of apoptotic cells when compared with eu- and hypothyroid mice. Remarkably, no signs of apoptosis were found in highly proliferative regions of tumors, explaining their intense growth. Altogether these results suggest that hypothyroidism creates an immunosuppressive milieu that allows for immune tolerance toward metastasizing tumor cells. Another indication of immune tolerance is reduced accumulation of NK cells in spleens from hypothyroid animals suggestive of reduced ability to remove tumor cells by NK cells (95).

\section{In vivo Studies in Other Cancer Models}

Protective effect of hypothyroidism was also shown for uveal melanoma, one of the most common and highly metastatic intraocular malignancies (84). PTU-induced hypothyroidism significantly improved survival of mice with ocular melanoma, in contrast to hyperthyroid animals that demonstrated significantly shorter survival when compared to euthyroid animals. Remarkably, uveal melanoma cells expressed high levels of $\alpha v$ and $\beta 3$ subunits of the integrin receptor, thus providing the platform for binding of T4 and activation of pro-proliferative intracellular signaling cascades.

Studies on the effects of TH on sarcoma brought conflicting results with early studies demonstrating that thyroid radioablation did not change growth of fibrosarcomas in mice (123), while in another reporting that hyperthyroidism attenuated growth of sarcoma tumors in mice (124). However, these results were later negatively verified by independent studies which showed that T4-induced hyperthyroidism stimulated growth and metastatic progression of sarcoma xenografts in mice, while tumor growth was attenuated in mice rendered hypothyroid by radioablation of the thyroid gland (88).

Antitumor effects of T3 were shown for basal cell carcinoma (BCC), the most common human cancer. Topically applied T3 significantly reduced tumor growth in mouse model of BCC (85). Intracellular T3 levels are regulated by activity of type 3 deiodinase (D3) which degrades T3. Depletion of D3 in skin of BCC bearing mice significantly reduced the occurrence of tumors, suggesting that antitumor T3 actions are mediated via its intracellular activity and not mediated by $\alpha \mathrm{v} \beta 3$ integrin receptor (125).

In contrast, plasma membrane-initiated $\mathrm{TH}$ signaling is welldocumented in a mouse model of follicular thyroid carcinoma (FTC). FTC tumors are spontaneously developed by Thrb ${ }^{\mathrm{PV} / \mathrm{PV}}$ mice in which both alleles of thyroid hormone receptor $\beta$ bear PV mutation that initially was identified in a patient with thyroid hormone resistance. TR $\beta$ with PV mutation are unable to bind $\mathrm{T} 3$ and activate transcription. Treatment of Thrb ${ }^{\mathrm{PV} / \mathrm{PV}}$ mice with PTU reduced the expression of integrin $\alpha \mathrm{v}$ subunit, thus leading to attenuation of TH-plasma membrane signaling, including the cascade involving PI3K, AKT, and $\beta$-catenin (81). This in turn 
resulted in inhibition of cancerous proliferation and reduction of tumor growth.

In conclusion, the in vivo studies in animal models indicate that $\mathrm{TH}$ have broad effects on cancer development and progression. On one hand, local intracellular changes in $\mathrm{TH}$ concentrations contribute to proliferation of cancer cells, stimulating tumor growth. On the other hand, extracellular hypothyroid milieu may support cancer progression by attenuating immune responses. Several lines of evidence strongly indicate that non-genomic T4 actions can trigger cancerous proliferation and that interference with $\mathrm{T} 4-\alpha \mathrm{v} \beta 3$ integrin binding can provide efficient therapeutic option for patients.

\section{CLINICAL STUDIES OF THE THYROID-CANCER ASSOCIATION}

This section summarizes clinical studies on the thyroid hormonecancer association, presented in Table 2. A detailed list of clinical studies, including study design and number of patients, is presented in Supplemental Table 3.

\section{Effect of Thyroid Status on Cancer Risk} Effect on the Overall Risk of Cancer

Hellevik et al. conducted a prospective population based study of 26,691 people without a previously diagnosed thyroid disease (153). Baseline TSH levels were measured and 9 years of follow up of cancer incidence was recorded. Compared to euthyroid reference group, increased cancer risk (HR 1.34) was associated with low TSH levels $(<0.5 \mathrm{mU} / \mathrm{l})$, a risk driven by lung cancer (HR 2.34) and prostate cancer (HR 4.99). In another population based cohort study, 17,034 patients with newly diagnosed hyperthyroidism were matched with 34,066 patients without hyperthyroidism. Over a 4 year follow up period, patients with hyperthyroidism were at higher overall risk of cancer (Adjusted HR 1.2, $p<0.05$ ) and thyroid cancer (Adjusted HR 6.8, $p<0.05$ ), with extended duration of hyperthyroidism associated with greater risk of thyroid cancer (195). The Rotterdam study prospectively included 10,318 patients with baseline measurements for free T4 and TSH, followed for a median of 10.4 years. Higher free T4 levels were associated with higher risk of solid cancers (HR 1.42 per unit increase in free T4), lung cancer (HR 2.33), and breast cancer (HR 1.77), although no association were found for TSH levels (126). Collectively, these prospective studies support a causal association between disorders in thyroid hormones and cancer risk.

\section{Effect on the Risk of Breast Cancer}

In a population based case control study including 676 breast cancer patients and 680 controls (127), free T4 levels were associated with a high overall risk of breast cancer (OR 1.4 for free $\mathrm{T} 4$ above vs. below the median). This increase was later attributed to a higher incidence rate of less aggressive breast cancer subgroups (128). Another prospective cohort study conducted by the same group included 2,185 women followed for an average of 19.3 years for breast cancer incidence (135). An association was demonstrated between T3 and breast cancer
TABLE 2 | Clinical studies on thyroid function and cancer.

\begin{tabular}{|c|c|c|}
\hline Cancer type & $\begin{array}{l}\text { Thyroid function/ } \\
\text { Treatment }\end{array}$ & Clinical outcome \\
\hline \multirow[t]{8}{*}{ Breast } & Hyperthyroidism & $\begin{array}{l}\text { Increased risk (126-129), higher mortality } \\
\text { (130, 131). Higher T3 (132, 133) and T4 } \\
(23,132-134) \text { in cancer patients. T3 } \\
\text { associated with cancer risk }(135,136) \text {, } \\
\text { large tumors (135), lymph node } \\
\text { metastases (135), and cancer death } \\
(137,138)\end{array}$ \\
\hline & & No effect on cancer risk (139-141) \\
\hline & Hypothyroidism & $\begin{array}{l}\text { Decreased risk (129, 142, 143), longer } \\
\text { progression free survival (144), later } \\
\text { diagnosis (142), more localized disease } \\
\text { (142), less lymph node involvement (142) } \\
\text { Lower mortality (145). Decreased risk of } \\
\text { triple+ BC with higher TSH (146) }\end{array}$ \\
\hline & & Increased risk (147) \\
\hline & & $\begin{array}{l}\text { No effect on cancer risk } \\
(139-141,148,149)\end{array}$ \\
\hline & LT4 treatment & Increased risk $(147,150)$ \\
\hline & & Lower all-cause mortality (151) \\
\hline & & No effect on cancer risk (152) \\
\hline \multirow[t]{2}{*}{ Prostate } & Hyperthyroidism & $\begin{array}{l}\text { Increased risk (153, 154), T3 associated } \\
\text { with risk of recurrence (155). Higher T3 in } \\
\text { cancer patients (156) }\end{array}$ \\
\hline & Hypothyroidism & Lower risk $(154,157)$ \\
\hline \multirow[t]{3}{*}{ Lung } & Hyperthyroidism & $\begin{array}{l}\text { Increased risk (126, 153). Higher T4 and } \\
\text { lower TSH in cancer patients (158) }\end{array}$ \\
\hline & Hypothyroidism & $\begin{array}{l}\text { Longer survival }(159,160) \text { and later } \\
\text { diagnosis }(159)\end{array}$ \\
\hline & LT4 treatment & Increased risk (161) \\
\hline Ovary & Hyperthyroidism & $\begin{array}{l}\text { Increased risk (162), higher mortality } \\
(130,163) . \text { Higher T4 in cancer patients } \\
(164)\end{array}$ \\
\hline Uterine & Hypothyroidism & $\begin{array}{l}\text { Increased mortality (165), Elevated TSH } \\
\text { associated with lower survival (166) }\end{array}$ \\
\hline \multirow{3}{*}{$\begin{array}{l}\text { Central } \\
\text { nervous } \\
\text { system }\end{array}$} & Hyperthyroidism & Increased risk (167) \\
\hline & T3 treatment & Prolonged survival (168) \\
\hline & $\begin{array}{l}\text { Induced } \\
\text { hypothyroidism }\end{array}$ & Prolonged survival $(169,170)$ \\
\hline \multirow[t]{2}{*}{ Renal } & Hypothyroidism & $\begin{array}{l}\text { Increased survival (171-178), increased } \\
\text { remission (173), tumor regression (179), } \\
\text { and response to treatment (180) }\end{array}$ \\
\hline & & Increased risk (167) \\
\hline $\begin{array}{l}\text { Esophageal } \\
\text { cancer }\end{array}$ & Hyperthyroidism & Higher incidence in cancer (181) \\
\hline \multirow[t]{3}{*}{ Pancreas } & Hyperthyroidism & $\begin{array}{l}\text { Increased risk (182), increased mortality } \\
\text { (165) }\end{array}$ \\
\hline & LT4 treatment & $\begin{array}{l}\text { Higher perineural invasion (62), T stage } \\
\text { (62), nodal spread (62) and poorer } \\
\text { prognostic stage (62) }\end{array}$ \\
\hline & $\begin{array}{l}\text { Induced } \\
\text { hypothyroxinemia }\end{array}$ & Tumor regression (183) \\
\hline Colorectal & Hyperthyroidism & Increased risk (184) \\
\hline
\end{tabular}

(Continued) 
TABLE 2 | Continued

\begin{tabular}{|c|c|c|}
\hline Cancer type & $\begin{array}{l}\text { Thyroid function/ } \\
\text { Treatment }\end{array}$ & Clinical outcome \\
\hline & Hypothyroidism & $\begin{array}{l}\text { Increased risk in untreated hypothyroidism } \\
\text { (184). Higher subclinical hypothyroidism in } \\
\text { colorectal cancer (185). Increased risk with } \\
\text { higher TSH (186) }\end{array}$ \\
\hline & LT4 treatment & Decreased risk $(184,187,188)$ \\
\hline & $\begin{array}{l}\text { Free T3/free T4 } \\
\text { ratio }\end{array}$ & $\begin{array}{l}\text { Higher ratio associated with increased } \\
\text { survival (189) }\end{array}$ \\
\hline \multirow[t]{4}{*}{ Hepatocellular } & Hyperthyroidism & $\begin{array}{l}\text { Low TSH associated with smaller tumors } \\
\text { (190). T3 and T4 inversely associated with } \\
\text { cancer mortality (191) }\end{array}$ \\
\hline & & Lower survival with elevated T4 (190) \\
\hline & Hypothyroidism & $\begin{array}{l}\text { Increased risk (192). High TSH associated } \\
\text { with larger tumors (190). Increased } \\
\text { incidence in HCC patients of unknown } \\
\text { etiology (193) }\end{array}$ \\
\hline & $\mathrm{TSH} \times$ free $\mathrm{T} 4$ & $\begin{array}{l}\text { Higher value associated with favorable } \\
\text { time to tumor progression and overall } \\
\text { survival if chemotherapy provided and } \\
\text { unfavorable TTP and OS if sorafenib } \\
\text { administered (194) }\end{array}$ \\
\hline Thyroid & Hyperthyroidism & Increased risk $(167,195)$ \\
\hline $\begin{array}{l}\text { Head and } \\
\text { neck }\end{array}$ & Hypothyroidism & Increased survival (196-198) \\
\hline Melanoma & Hypothyroidism & No difference in survival (199) \\
\hline $\begin{array}{l}\text { Multiple } \\
\text { myeloma }\end{array}$ & Hyperthyroidism & T3 higher and TSH lower in patients (200) \\
\hline \multirow[t]{2}{*}{ Leukemia } & Hyperthyroidism & $\begin{array}{l}\text { T3 and T4 higher and TSH lower in } \\
\text { patients (201). Improved outcome in } \\
\text { Grave's disease (202) }\end{array}$ \\
\hline & Hypothyroidism & $\begin{array}{l}\text { Improved outcome in Hashimoto } \\
\text { thyroiditis (202) }\end{array}$ \\
\hline $\begin{array}{l}\text { Myelodysplastic } \\
\text { syndrome }\end{array}$ & Hyperthyroidism & $\begin{array}{l}\text { T3 and T4 higher and TSH lower in } \\
\text { patients (203) }\end{array}$ \\
\hline \multirow[t]{6}{*}{ General } & Hyperthyroidism & $\begin{array}{l}\text { Increased risk (126, 153, 195), Increased } \\
\text { cancer death in hyperthyroidism (165), and } \\
\text { toxic nodular goiter (204) }\end{array}$ \\
\hline & & $\begin{array}{l}\text { T3 inversely associated with cancer } \\
\text { mortality (191) }\end{array}$ \\
\hline & & $\begin{array}{l}\text { No association to cancer mortality } \\
(205,206)\end{array}$ \\
\hline & Hypothyroidism & $\begin{array}{l}\text { Lower mortality }(145,207) \text {, Longer survival } \\
\text { (208), High response to radiation therapy } \\
\text { (209) }\end{array}$ \\
\hline & & $\begin{array}{l}\text { Increased risk (167), Increased cancer } \\
\text { mortality (137) }\end{array}$ \\
\hline & $\begin{array}{l}\text { Induced } \\
\text { hypothyroxinemia }\end{array}$ & Prolonged survival (210) \\
\hline
\end{tabular}

risk (HR 1.61 of third quartile compared to first). In another large population-based study conducted by Søgaard et al., women with hyper- and hypothyroidism were followed for up to 7.4 years (129). Hyperthyroidism was related to a slight increase in the risk of breast cancer compared to the general population (SIR 1.11), while the opposite was shown for hypothyroidism (SIR 0.94). In a retrospective cohort study of 437 breast cancer patients, elevated levels of TSH were associated with a lower likelihood of triple positive breast cancer (ER+ PR+ Her2/neu+) compared with $\mathrm{ER}+\mathrm{PR}+\mathrm{Her} 2 /$ neu- breast cancer. However, no association was found with tumor grade or stage (146). Interestingly, Brandt et al. were recently able to identify a SNP (rs2235544) in the gene for deiodinase type 1 (DIO1) which was associated with both free T4 level and breast cancer risk (211). A recently published case control study which included 682 breast cancer patients and 731 controls demonstrated an association between higher serum total T4 and breast cancer in both premenopausal (OR 5.98 ) and post-menopausal women (OR 2.81), whereas a negative association was demonstrated between total $\mathrm{T} 3$ and breast cancer (134). Similarly, Huang et al. demonstrated higher free T4 and lower T3 in patients with newly diagnosed breast cancer compared with patients with benign breast lesions (23). However, these findings may demonstrate the effect of malignancy on the thyroid axis, rather than a true demonstration of risk or causality. Specifically, malignancy may be associated with a reduction of T3, resulting the so-called non-thyroidal illness syndrome (NTIS) (212). The association between NTIS and malignancies is later detailed in this review in a designated section. A meta-analysis from 2012, which included 10 case control studies of hyper- and hypothyroidism and breast cancer, failed to find a putative relationship of either disorder. Notably, a high degree of heterogeneity was demonstrated between the six hypothyroidism studies included (139). Another meta- analysis from 2017 included population based studies assessing thyroid dysfunction and the risk of breast cancer. Analysis of 12 studies, including 24,571 cases, also did not find a statistical correlation between hypothyroidism and breast cancer $(p=0.162)$. Similarly, by analyzing 10 studies, which included 21,889 cases, the authors did not demonstrate a statistically significant higher risk of breast cancer in hyperthyroid patients (140).

\section{Effect on the Risk of Prostate Cancer}

In a prospective cohort study, sera from 3649 patients were assayed for TSH and free T4 (154). During a 20 year follow up period, $7.8 \%$ of males were diagnosed with prostate cancer. Higher TSH was associated with a lower risk of prostate cancer (adjusted HR: 0.7 per $1 \mathrm{mIU} / \mathrm{L}$ increase in TSH). Similarly, higher free $\mathrm{T} 4$ was associated with increased risk of prostate cancer (adjusted HR: $1.11 \mathrm{per} 1 \mathrm{pmol} / \mathrm{L}$ increase). In a prospective study of male smokers including 402 prostate cancer patients and 800 controls (157), TSH in the highest quintile was associated with decreased risk of cancer (Q5 vs. Q1-4: OR 0.7). Hypothyroid men (high TSH with normal or low T4) had lower prostate cancer risk compared to euthyroid men (OR 0.48).

\section{Effect on the Risk of Gynecologic Cancers}

In a population based case-control study, 767 patients with recent diagnosis of epithelial ovarian cancer were compared with 1,367 community controls (162). Based on data retrieved from interviews, hyperthyroidism history was linked with increased cancer risk (OR 1.8). In another study, Kang et al. evaluated the association of self-reported history of thyroid dysfunction with medical records of confirmed endometrial carcinoma $(n=$ $1,314)$ and ovarian cancer $(n=1,150)$ as part of the Nurses' 
Health Study (NHS). In this case, history of hypothyroidism or hyperthyroidism was not associated with cancer risk (213). Lastly, in a retrospective study Brinton et al. assessed the relationship between hospital and outpatient admission for various conditions and subsequent development of uterine and ovarian cancer. A prior diagnosis of thyroid disease was associated with uterine cancer (RR 1.52). However, no specific type of thyroid disease was more strongly linked to risk than others (214).

\section{Effect on the Risk of Gastrointestinal Cancers}

In a large population based case control study by Ko et al., 532 patients with pancreatic cancer were matched to 1,701 controls randomly selected from the same population (182). Based on patient self-report, hyperthyroidism history was related with increased cancer risk (OR 2.1).

Unlike pancreatic cancer, data regarding colorectal cancer (CRC) and hepatocellular carcinoma (HCC) produced conflicting results. A single prospective population based study suggested an association between hyperthyroidism and an increased risk of CRC (153), but due to a small cohort, this increase was not statistically significant. In contrast, additional studies demonstrated that hypothyroidism was associated with increased risk of colon cancer. A large case-control study compared 20,990 colorectal cancer (CRC) patients and 82,054 matched controls from a population database, followed for an average of 6.5 years and determined CRC risk in patients with thyroid dysfunction (184). In this study both hyperthyroidism (OR 1.21) and untreated hypothyroidism (OR 1.16) were associated with increased risk of colorectal cancer. Chan et al. conducted a prospective case-control study of 3,836 older men (186). Over a median follow up period of 9 years, 136 men developed colorectal cancer. Following adjustments, higher TSH was related with increased incidence of colorectal cancer (SHR 1.19), an association which was reinforced after eliminating the first year of follow up (SHR 1.23). Free T4 was not associated with cancer incidence in this study.

Similar to CRC, hypothyroidism may also play a role in liver carcinogenesis. Hassan et al. conducted a case-control study including 420 patients with hepatocellular carcinoma and 1,104 healthy controls (192). Hypothyroidism of longer than a decade was associated with significantly higher risk of HCC in women, unrelated to known HCC risk factors (OR 2.9 following regression analysis for risk factors). However, the data on thyroid disorders was based on patient selfreport using questionnaires rather than thyroid hormone levels. Reddy et al. (193) demonstrated that in 160 patients with HCC, hypothyroidism was more prevalent in HCC of unknown etiology compared to patients with HCC secondary to HCV or alcoholic liver disease (OR 6.8).

The inverse correlation between thyroid function and cancer risk observed in CRC and HCC may be attributed to the elevation of TSH under hypothyroid state. The overexpression of a functioning thyroid stimulating hormone receptor (TSHR), which was demonstrated in HCC tissues (215), may provide a possible mechanism. TSH elevation in hypothyroidism may lead to HCC progression through direct stimulation of its receptor on cancer cells. However, no documentation for a similar TSHR expression in CRC was reported to date.

\section{Effect on the Risk of Hematologic Malignancies}

Dalamaga et al. compared 73 patients with primary multiple myeloma to 73 matched controls admitted for non-neoplastic conditions (200). The prevalence of clinical thyroid disease was higher in multiple myeloma patients compared to controls (adjusted OR 4.03 for thyroid disease, 5.68 for autoimmune thyroid disease). The levels of free T3 was higher (3.5 vs. 2.7 $\mathrm{pg} / \mathrm{ml}, p=0.002)$ and TSH lower (2.2 vs. $3.1 \mu \mathrm{IU} / \mathrm{ml}, p=$ 0.001 ) in myeloma patients compared to controls, albeit within the normal range. The same group conducted a case control study of 101 patients with histologically and cytogenetically confirmed MDS to 101 matched control. MDS patient had significantly higher serum levels of free T3 and free T4 and lower TSH than controls (203). A small case control study compared thyroid hormone levels between 25 patients with acute leukemia and 25 matched controls. Total T3, free T3, total $\mathrm{T} 4$, and free $\mathrm{T} 4$ were higher in patients than control, within the normal range, while TSH levels were significantly lower (201). However, since TH levels were not determined prior to the development of disease, an assessment of risk could not be established.

\section{Effect of Thyroid Hormones on Clinical Presentation of Cancer}

Cristofallini et al. retrospectively compared 1,136 women with breast cancer with 1,088 controls (142). Prevalence of hypothyroidism was significantly lower in the cancer group compared to the control group ( 7.0 vs. $14.9 \%, p<0.001$ ). Hypothyroid breast cancer patients were diagnosed at an older age (58.8 vs. 51.1 years; $p<0.001$ ), had higher probability for having a localized disease $(95.0$ vs. $85.9 \%$ clinical T1 or T2 disease, respectively; $p=0.025)$, and were more likely to be lymph node negative (62.8 vs. $54.4 \%$; $p=0.15)$. While these findings suggest that hypothyroidism slows breast cancer progression, the study was limited by its retrospective nature and by the fact that the diagnosis of hypothyroidism was based on information from medical charts rather than hormone values. In the aforementioned study by Tosovic et al. (135), higher T3 level (third quartile compared to first) was associated with large breast tumors ( $>20 \mathrm{~mm}$ ) (HR of 3.17) and lymph node metastases (HR 4.53). This association was especially pronounced in post-menopausal women. In a series by Atkins et al. 34 patients with various advanced neoplasms (melanoma, renal cell carcinoma, lymphoma, and colon cancer) had received treatment with interleukin-2 and lymphokine-activated killer (LAK) cells (179). Twenty-one percent of patients had laboratory evidence of hypothyroidism. Patients with hypothyroidism had a higher rate of tumor regression (71 vs. $19 \%, p<0.02$ ).

Conversely, hypothyroidism was associated with increased aggressiveness of colorectal and liver cancer, comparable with the effect on cancer risk. In a case control study comparing 273 colorectal cancer patients to 819 matched controls, the prevalence of subclinical hypothyroidism was significantly higher in the colorectal neoplasm group (24.5 vs. $15.3 \%, p<0.01$ ). 
Compared with euthyroid subjects, hypothyroid patients had higher likelihood of advanced colonic disease ( 8.3 vs. $4.4 \%, p$ $=0.028$ ) (185). In another study by Pinter et al., 667 patients diagnosed with non-surgically treated HCC were retrospectively followed for a mean period of 65.5 months (190). Hypothyroid patients (TSH>3.77 $\mu \mathrm{U} / \mathrm{ml}$ ) had a higher risk for large lesions $(>5 \mathrm{~cm})$, while Hyperthyroid patients $(\mathrm{TSH}<0.44 \mu \mathrm{U} / \mathrm{ml}$ ) had a lower risk.

\section{Effect of Thyroid Status on Cancer Survival Effect on Overall Cancer Survival}

Several population based studies have demonstrated increased cancer mortality in hyperthyroidism, with opposite outcomes in hypothyroidism, supporting the assumption of growth promoting effect of thyroid hormones. Brandt et al. used data of 2,152 patients with Grave's disease and toxic nodular goiter, followed for 11 years (204). Both diseases were associated with increased all-cause mortality compared with non-hyperthyroid controls, and increased cancer mortality was demonstrated for toxic nodular goiter (HR 1.36, $p<0.05$ ). In a recent population based study by Journy et al., 75,076 female radiologic technologists who completed medical questionnaires were retrospectively followed for a median of 28 years (130). No association was demonstrated between overall cancer mortality and hyper or hypothyroidism. However, risk of breast cancer mortality after 60 years of age was increased in patients with self-reported hyperthyroidism (HR 2.04, $p<0.05$ ). Women with hyperthyroidism treated with radioactive iodine had increased risk of ovarian cancer mortality compared with women without thyroid disease (HR 5.32, $p<0.05$ ), based on very few cases. Lechner et al. (216) conducted a retrospective cohort study of 538 patients with various solid malignancies (renal cell carcinoma, GIST, HCC, neuroendocrine, primary central nervous system, other carcinoma, sarcoma) treated with tyrosine kinase inhibitors. Thirteen percent of patients developed subclinical hypothyroidism and 27\% developed overt hypothyroidism. Patients with hypothyroidism had significantly longer overall survival (median overall survival 1,005 days in subclinical hypothyroidism and 1,643 in overt hypothyroidism compared with 685 days in euthyroid patients, $p<0.0001$ ). In Franklyn et al.'s retrospective cohort of hyperthyroid patients treated with radioiodine (217), mortality from cancers of all sites was reduced following treatment (SMR 0.9, $p=0.02$ ). In subgroup analysis lower mortality was significant only for cancer of the bronchus and trachea (SMR 0.78, $p=0.03$ ) while for cancers of the small bowel and thyroid, small absolute risk increases in mortality were demonstrated. Opposing results were demonstrated in a large population based study, wherein 115,746 patients were followed for 10 years for evaluation of cancer mortality (137). Following adjustment, patients with biochemically proved subclinical hypothyroidism (1.6\%) at study inclusion had higher risk of cancer death (RR 1.51, $p<0.05$ ) as well as increased risk of bone, skin and breast cancer (RR 2.79, $p<0.05$ ). A prospective study by Zhang et al. (191) was conducted on a cohort of 212,456 middle aged Korean subjects who had undergone thyroid function tests. Following a median follow-up of 4.3 years, an inverse association was demonstrated between free T4 and all-cause mortality $(\mathrm{HR}=0.77, P=0.01)$ as well between free $\mathrm{T} 3$ and cancer mortality $(\mathrm{HR}=0.62, p$ for trend $=0.001$ ). TSH was not associated with mortality endpoints. This discrepancy may be at least partially attributed to the large proportion of gastrointestinal tumors in both studies $(>45 \%$ of cancer deaths) which, as described above, may propagate in hypothyroid conditions.

\section{Effect on Breast Cancer Survival}

In 1964, Humphrey and Swerdlow were among the first to demonstrate the effect of thyroid disorders on breast cancer outcomes (218). In their study, the 5-year survival of 14 patients who had undergone a thyroidectomy for non-toxic goiter was significantly longer than nine patients who had undergone thyroidectomy for hyperthyroidism (71 vs. $22 \%, p<0.05$ ). In another study of 462 cases of breast cancer (131), patients with a history of thyroid disease had significantly lower survival rates at 5 and 10 years compared with controls $(p<0.005)$. In a subgroup analysis, patients with a history of treated hyperthyroidism had significantly shorter 5- and 10-year survival $(p<0.01)$. A population-based prospective cohort study by Tosovic et al. included 2,185 women who had T3 levels measured as part of a preventive health study (138). After a mean follow-up of 24.1 years, 26 women died of breast cancer. T3 levels were correlated with age-adjusted breast cancer related death ( $\mathrm{HR} 2.8, p=0.012)$, especially in post-menopausal patients (adjusted HR 3.73, $p=$ 0.001 ). Thyroid hormone status may also affect response to breast cancer therapy. A study by Cao et al. included 28 patients with metastatic breast cancer treated with the VEGFR-2 inhibitor famitinib (144). Sixty-four percent of patients had elevated TSH ( $>4.94 \mathrm{mIU} / \mathrm{L}$ ) during treatment. Progression free survival (PFS) was longer in these patients compared with patients with normal TSH (107 vs. 53 days, respectively, $p=0.002$ ).

\section{Effect on Lung Cancer Survival}

Several decades ago, Hercbergs and Leith reported a case of a 69 year old male with metastatic non-small cell lung cancer that resolved spontaneously following resuscitation from myxedema coma, dying of unrelated causes 4 years after the myxedema event (5). In a later retrospective case-controls study (159), Hercbergs et al. compared 85 hypothyroid lung cancer patients to 85 matched euthyroid lung cancer patients. Hypothyroid patients were older at diagnosis (median age 73 vs. 64 years, $p=0.0006$ ) and survived longer (stages $1-4: 14.5$ vs. 11.1 months, $p=0.014$; stage $4: 11$ vs. 5 months, $p=0.0018$ ) compared with controls. In a recent study of 51 non-smallcell lung cancer patients treated with pembrolizumab, a PD1 inhibitor (160), 21\% of patients developed hypothyroidism requiring thyroid hormone replacement, with $80 \%$ developing positive antithyroid antibodies. Overall survival (OS) with pembrolizumab was significantly longer in subjects who developed thyroid dysfunction (mean OS 40 vs. 14 months. HR $0.29, p=0.04$ ).

\section{Effect on Ovarian Cancer Survival}

Minlikeeva et al. used collective data from 11 studies, including information on thyroid hormone status for a total of 5,822 
patients diagnosed with invasive ovarian cancer (163). Increased risk of mortality was demonstrated for patients with a history of hyperthyroidism in the 5 years preceding cancer diagnosis (HR $=1.94 ; p=0.01$ ). Hypothyroidism was associated with a mildly decreased mortality risk $(\mathrm{HR}=1.16 ; p=0.01)$. Duration of hypothyroidism or thyroid medications use were not associated with survival.

\section{Effect on Renal Cancer Survival}

Much research has been conducted on the possible positive effects of drug-induced hypothyroidism on the outcome of treatment for renal cell carcinoma (RCC). In a small scale study by Weijl et al. (180), patients with metastatic renal cell carcinoma were treated with IL-2 and LAK cells. Forty-seven percent of patients became hypothyroid following treatment. Favorable response to treatment was positively correlated with hypothyroidism $(r=0.76, p=0.001)$.

Over the past decade, several studies have reported on potential favorable outcomes of tyrosine-kinase inhibitors (TKI's)-induced hypothyroidism, specifically by sunitinib. Sunitinib is an oral multitargeted tyrosine kinase inhibitor commonly used in metastatic renal cell carcinoma. Hypothyroidism is a common side effect of this treatment, with up to $85 \%$ patients developing abnormality of thyroid function consistent with hypothyroidism, and roughly a third requiring thyroid hormone replacement $(219,220)$. The mechanism for this effect is not altogether clear, though it may be related to a decreased VEGF binding to normal thyroid cells and/or disruption of thyroid blood flow (219). In a retrospective analysis of metastatic RCC patients who received VEGF receptor tyrosine kinase inhibitors (171), median OS and PFS were significantly longer in patients with a peak TSH $>10 \mathrm{mIU} / \mathrm{L}$ compared to patients with a peak TSH of $\leq 10 \mathrm{mIU} / \mathrm{L}$ (not reached vs. 21.4 months, $p=0.005 ; 47.7$ vs. 9.3 months, $p=$ 0.009 , respectively). In a series of sunitinib-treated clear cell RCC (172), hypothyroid ( $\mathrm{TSH}>4 \mathrm{mIU} / \mathrm{L}$ ) patients receiving levothyroxine as thyroid-replacement therapy had prolonged PFS compared with other patients (25.3 vs. 9.0 months; $p=$ 0.042 ). A prospective cohort study by Schmidinger et al. included 87 sunitinib or sorafenib treated patients with metastatic RCC (173). Patients who developed subclinical hypothyroidism had a higher rate of remission compared with euthyroid patients $(28.3$ vs. $3.3 \%, p<0.001)$ and longer median duration of survival (not reached vs. 13.9 months, $p=0.016$ ). Other studies have similarly demonstrated prolonged PFS in sunitinib induced hypothyroidism $(174,175)$. One prospective study did not show such a correlation (221). However, this study was based on only 6 months of follow up. In 2015, Nearchou et al. published a meta-analysis evaluating hypothyroidism as a predictive marker for survival in metastatic RCC patients treated with TKI's (176). Based on six studies, PFS in patients with sunitinib-induced hypothyroidism was not significantly different compared with patients without hypothyroidism. However, in three studies which included patients treated with sunitinib or sorafenib, the difference in PFS was statistically significant in favor of patients with acquired hypothyroidism (HR, 0.59; $p=0.003)$. Moreover, an analysis of four studies indicated a statistically significant improvement in OS in patient who developed sunitinibinduced hypothyroidism compared with patients who did not (HR 0.52, $p=0.01$ ).

\section{Effect on Gastrointestinal Cancer Survival}

Similar to the effect on cancer risk, CRC and HCC appear to represent cancer subtypes whose association with thyroid status differs from that of other solid tumors. In a recent study by Schirripa et al. (189), a higher baseline free T3/free T4 ratio was associated with increased survival in patients with metastatic colorectal cancer treated with the multikinase inhibitor regorafenib $(p=0.003)$. In Pinter et al.'s study of non-surgically treated HCC patients (190), increased OS was associated with lower TSH ( $\leq 1.7$ vs. $>1.7 \mu \mathrm{U} / \mathrm{ml}$, median OS 12.3 vs. 7.3 months; $p=0.003$ ) and lower free $\mathrm{T} 4$ ( $\leq 1.66$ vs. $>1.66$ ng/dl, median OS, 10.6 vs. 3.3 months; $p=0.007)$. Similarly, in a study by Zhang et al. (191), both free T3 and free T4 were inversely associated with liver cancer mortality (HR per SD change: 0.64 for free T3, 0.52 for free T4). These findings again support a growth promoting effect of hypothyroidism in HCC, which may be related to activation of the TSH receptor. In a recent case control study (194), the product of TSH and free T4 was calculated for 123 patients with advanced HCC treated with sorafenib or chemotherapy. High TSH x free T4 at baseline ( $>2.48$ ) was associated with favorable time to tumor progression (TTTP) (HR 0.478, $p=0.008$ ) and better OS if chemotherapy was provided (HR 0.44, $p=0.006$ ). Conversely, high baseline TSH $x$ free T4 $(>2.55)$ was associated with unfavorable TTTP (HR 2.03, $p=0.039$ ) and overall survival (HR 3, $p=$ $0.007)$ if sorafenib was administered. However, the association between this calculated ratio and thyroid status was not fully elucidated.

\section{Effect on Head and Neck Cancer Survival}

Head and neck cancer patients commonly undergo involved-field radiation therapy and are prone to iatrogenic hypothyroidism, which can therefore serve as a useful model to study the effect of thyroid dysfunction on cancer outcomes. Nelson et al. conducted a retrospective analysis of 155 patients with advanced head and neck squamous cell carcinoma who were treated with radiation therapy alone or in combination with other treatments (196). Patients who developed new onset hypothyroidism posttreatment had less cancer recurrence $(p=0.02)$, improved survival $(p<0.001)$, and longer recurrence-free survival $(p$ $<0.001$ ), compared with patients who did not. In another population based study of patients with head and neck cancer treated with radiotherapy (197), the 10 year incidence of hypothyroidism was 59\% and these patients exhibited longer survival (HR 0.42, $p<0.001$ ) as well as longer cause-specific survival (HR 0.36, $p<0.001$ ). In a phase III trial comparing two cisplatin chemoradiotherapy protocols in 300 patients with locally advances head and neck cancer (222), 38.73\% of patient developed hypothyroidism by 2 years of follow up (198). These patients had lower locoregional failure rate (LRFR) (hazard ratio $0.342, p=0.043$ ), and longer overall survival (hazard ratio $0.336, p=0.001)$. Favorable impact on LRFR, PFS and OS were 
associated with hypothyroidism of longer duration and TSH levels up to $40 \mathrm{mIU} / \mathrm{L}$.

\section{Association Between Thyroid Autoimmunity and Cancer}

Small scale case control studies have demonstrated an increased prevalence of thyroid autoimmunity in breast cancer $(223,224)$, gastric cancer (225), pancreatic cancer (226), multiple myeloma (200), and myelodysplastic syndrome (203). In a 2012 metaanalysis, autoimmune thyroiditis, as well as overall thyroid antibody positivity, thyroglobulin antibody positivity and thyroid peroxidase antibody (TPOAb) positivity were associated with increased risk of breast cancer (OR 2.92, 2.02, 2.72, 2.64, respectively), with minimal to moderate heterogeneity (139). Conversely, in a population based case control study by Brandt et al. (128), including 676 breast cancer patients and 680 controls, women with high levels of TPOAb (above $9 \mathrm{kIU} / \mathrm{L}$ ) were at a lower risk of being diagnosed with breast cancer (OR 0.75), specifically invasive type (OR 0.74).

Thyroid autoimmunity may beneficially affect cancer outcomes. Fiore et al. (227) examined the prognostic value of thyroid autoantibodies in 47 patients with locally metastatic breast cancer referred for mastectomy. Five-year mortality was lower in patients with thyroid autoantibody positivity (6.7 vs. $46.9 \%, p=0.008$ ). Farahati et al. assessed anti TPOAb in 314 patients with newly diagnosed breast cancer (228). Among 56 patients with TPOAb, no incidences of distant metastasis was documented, whereas in $17(6.6 \%)$ of 258 cases without TPOAb, distant metastases were demonstrated $(p=0.04)$. In Brandt et al., high TPOAb levels were also associated with a lower risk of ductal cancer, large tumors $(>20 \mathrm{~mm})$, and ER and PR positive tumors (128). Interestingly, the same group recently identified several TPOAb related SNPs (s11675434, rs3094228, rs1033662, rs301806, and rs207140) which may also be associated with breast cancer risk (211). Another study by Franzke et al. included 329 patients with metastatic RCC treated with systemic IL-2 and IFN $\alpha 2$ (229). Antithyroid autoantibodies were detected in $18 \%$ of patients. Thyroid autoantibodies were correlated with increased survival (5-year survival 54 vs. $15 \%, p<0.0001)$. Interestingly, HLA-Cw7 expression was more frequent with thyroid autoantibody positivity (69.2 vs. 47.7\%, $p=0.009$ ), and Cw7 expression was associated with prolonged overall survival, suggesting HLA-dependent thyroid autoimmunity associated with improved cancer outcomes. Thyroid autoantibodies may affect breast cancer behavior irrespective of its effect on the thyroid hormone axis. Thyroid cells and benign and malignant breast tissues share common antigens. The most important of these is the sodium-iodine symporter, which is highly expressed in breast cancer cells (230). Also, lactoperoxidase in breast cancer cells shares a homology with thyroperoxidase (231). T cells directed against thyroid autoantigens could attack breast cancer cells expressing similar antigens (227).

\section{Association of Cancer With Non-thyroidal Illness Syndrome (NTIS)}

NTIS, or sick euthyroid syndrome, is characterized by alterations in circulating thyroid hormone levels in euthyroid patients with acute or chronic systemic illnesses. Changes include a decrease in T3 levels, increase in rT3 and inconstant alterations in circulating T4 levels (212). The association of NTIS with cancer was documented in various tumor types including breast cancer (232), gastrointestinal cancers (232), lung cancer (233235), central nervous system tumors (236), multiple myeloma (237), chronic lymphocytic leukemia (238), and diffuse large cell lymphoma (239).

NTIS may be associated with adverse disease outcomes. In a 1978 study by Ratcliff et al. (233), 6 month mortality was higher among lung cancer patients with low T3 compared with matched lung cancer patients with normal T3 (49 vs. 27\%). In a study of 80 patients with newly diagnosed non-small cell lung cancer (234), NTIS was more frequent among stage III (26\%) and stage IV $(62 \%)$ cases, and survival was shorter in patients with NTIS compared with patients without NTIS (mean survival 9.2 vs. 15.2 months, $p=0.00002$ ). Similarly, in a cohort of both small cell and non-small cell cancer patients, NTIS was associated with disease stage and served as a poor prognostic factor (235). In a study of 230 patients with primary brain tumors (236), 27\% had NTIS syndrome. Glioma patients with NTIS had greater 5year mortality $(\mathrm{HR}=2.197, p=0.016)$ and shorter OS (249 vs. 352 days; $p=0.029$ ). NTIS was also a predictor of poor postoperative outcomes in patients undergoing brain tumor surgery (240). In a study of patients with chronic lymphocytic leukemia (238), NTIS was associated with significantly shorter time to first treatment ( 2 vs. 11 months, $p<0.001)$ and cancer-specific survival (median survival 51 months vs. not reached) compared to patients with normal T3. In another study by the same group, of 188 patients with diffuse large B cell lymphoma, low T3 was associated with worse PFS (median survival 17 vs. 22 months) and overall survival (median survival 17 vs. 23 months) in the rituximab era (239). However, collectively these results may be a reflection of NTIS as a marker of aggressive disease, rather than a direct effect of this syndrome on cancer outcomes.

\section{The Association Between Thyroid Replacement Therapy and Cancer Incidence and Outcome}

In an early study, 5,505 patients referred to a mammography department were interviewed regarding thyroid hormone use (150). Six hundred thirty-five patients used thyroid medications. In patients receiving thyroid supplements, breast cancer incidence was significantly higher than controls without thyroid disease or thyroid medication use $(12.13$ vs. $6.2 \%, p<0.005)$. The difference was especially prominent in patients taking thyroid medication for more than 15 years (19 vs. 6.2\%, $p<0.005)$ and nulliparous women taking thyroid medication for more than 5 years (20 vs. $9.2 \%$ in nulliparous controls, $p<0.025)$. These findings suggest a relationship between thyroid supplements and cancer associated with the duration of use. In a prospective cohort study, 2,738 post-menopausal women were screened for thyroid hormone parameters and prospectively followed for a period of 9 years (147). New breast cancer was related to previous use of thyroid medication at study inclusion (OR 3.2). However, a meta-analysis from 2017 including six studies evaluating the relationship between thyroid hormone supplementation and risk 
of breast cancer found no statistical correlation between the two (140). In a population based study, Cornelli et al. compared the prevalence of breast, colorectal, gastric and lung cancer in women during 2010 with the sales of levothyroxine (LT4) in the previous year in 18 Italian regions (161). Corrected for smoking and age, a significant correlation was demonstrated for lung cancer and levothyroxine sales $(R=0.485, p=0.04)$. Sarosiek et al. performed a retrospective analysis in 504 pancreatic cancer patients who underwent a Whipple procedure or distal pancreatectomy and splenectomy during the course of 7 years (62). $14.1 \%$ of patients were hypothyroid. Hypothyroid patients taking exogenous thyroid hormone, in comparison to euthyroid patients, were more likely to have perineural invasion (OR 3.38, $p=0.012$ ), have high T stage (T3-T4, OR 2.1, $p=0.045$ ), nodal spread (OR 2.05, $p=0.018$ ), and have poorer prognostic stage (2B-3, OR $1.89, p=0.037)$. There was no difference in survival between both groups.

Similar to the apparent protective effect of endogenous thyroid hormones in colorectal cancer, exogenous thyroid hormone supplementation was associated with decreased risk of CRC. In a population based case control study conducted in northern Israel, 2,648 colorectal cancers were matched to 2,566 controls (187). Levothyroxine use for a minimum of 5 years, evaluated by structured interviews and prescription records validation, was associated with a significantly reduced risk of CRC (OR 0.59, $p=0.001$ ). However, this study was limited by possible recall bias. Another large population based study compared 20,990 colorectal cancer patient with 82,054 matched control patients (184) and determined CRC risk in patients with thyroid dysfunction, with and without thyroid hormone replacement. Thyroid hormone supplementation use of more than 5 years was related with lower risk for CRC, with a stronger association documented for longer periods since initiation of treatment. The adjusted odds ratio for colorectal cancer associated with thyroid hormone replacement was 0.88 $(p=0.03)$ for treatment initiated $5-10$ years before index date and $0.68(p<0.001)$ for treatment initiated more than 10 years before index date. In response to this study, Friedman et al. (188) performed a case-control analysis of colon $(n=$ $12,207)$ and rectal/rectosigmoid cancers $(n=4,729)$, based on the Kaiser permanente cancer registry, and obtained LT4 prescription dispensing records from outpatient pharmacies. Each case patient was matched to up to 50 control subjects. Rectal cancer risk was more than $30 \%$ lower in men who used levothyroxine for more than 5 years, compared to non-users (OR $0.66, p=0.03)$. Although statistically insignificant, colon cancer risk appeared to be somewhat reduced.

\section{The Effect of Induced Hypothyroidism and Hypothyroxinemia on Cancer Outcomes}

Few interventional studies exist which examined the effect of chemically induced hypothyroidism and hypothyroxinemia on cancer outcomes. Those are based mainly on case reports and small patient series. A previous report described a patient with inoperable glioblastoma of the optic chiasm who failed standard treatment with radiation and temozolomide (169). The patient underwent induced hypothyroidism with PTU, followed by carboplatin chemotherapy. On two separate occasions, this patient responded clinically and radiographically to treatment with an extended remission period (2.5 years) and prolonged overall survival (4.5 years). In a recent report (183), a patient with triple negative breast cancer and lung metastasis who progressed under chemotherapy was treated with methimazole $(45 \mathrm{mg}$ per day) and increasing doses of liothyronine (L-T3). This treatment led to stabilization of the disease and CA-125 levels for several months. A second patient described in this study with metastatic pancreatic adenocarcinoma was treated with a similar protocol. In this case, treatment led to a temporary reduction in CA199 and a disappearance of a skin metastasis. In both patients, although L-T3 produced early resistance to treatment, a direct tumor growth inhibition effect was also observed. In a study published in 1976 (168), Yung et al. compared 32 patients with glioblastoma treated with surgery and radiation alone with 18 glioblastoma patients treated with surgery, radiation as well T3 to achieve a hyperthyroid state. Patients in the T3 treatment group had significantly longer median survival (60 vs. 30 weeks, $p=0.005$ ). The authors speculated that this may be attributed to radiosensitizing property of triiodothyronine. Hercbergs et al. reported on 22 patients with recurrent glioma who were treated with PTU to induce hypothyroidism, concurrently with tamoxifen (170). Eleven patients became hypothyroid. Median survival was significantly longer in the hypothyroid group (10.1 vs. 3.1 months, $p=0.03$ ). Lastly, another study by Hercbergs et al. included 23 patients with end stage cancers of the brain, ovary, lung, pancreas, salivary gland, and breast as wells mesothelioma and soft-tissue sarcoma (210). In euthyroid patients, hypothyroxinemia was reached by using methimazole, with the addition of L-T3 to avoid hypothyroidism side-effects parallel to suppressing endogenous TSH. The survival time of $83 \%$ (19 of 23 ) of patients exceeded the $20 \%$ expected 1 -year survival for this group based on the SEER database $(p<0.01)$.

\section{THE EFFECTS OF THYROID HORMONES ON ANGIOGENESIS AND ANTICANCER IMMUNE RESPONSES}

Generation of dense vasculature and evasion of immune reaction are among the key hallmarks of cancer (241). Recent studies provide evidence that $\mathrm{TH}$ affect both these crucial features of tumors, enabling cancer progression.

T4 acting on $\alpha v \beta 3$ receptor stimulates formation of new vessels as shown in CAM assay and three-dimensional human microvascular endothelial sprouting model $(97,99,100)$ which involves activation of MAPK (97). Inhibition of T4- $\alpha \mathrm{v} \beta 3$ signaling by tetrac or anti-integrin antibody blocked $\mathrm{TH}$-induced formation of new vessels $(97,99)$. Importantly, tetrac and its nanoparticulate form also inhibited angiogenesis stimulated by cancer cells, as shown by CAM models implanted with renal cell cancer (59), medullary thyroid cancer (82), follicular thyroid carcinoma (83), and non-small cell lung cancer (40).

T4 may also facilitate cancer progression by interfering with anti-tumor immune responses. Treatment of breast and colon 
cancer cells with T4 stimulated the expression of PD-L1, one of the elements of PD-1/PD-L1 immune checkpoint that controls activation of T cells. Cancer cells often overexpress PD-L1 which interacts with $\mathrm{PD}-1$ receptors on the surface of $\mathrm{T}$ cells, thus blocking its activation and attenuating immune response directed against tumors (242). In breast cancer cells, T4 activated PDL1 expression via non-genomic mechanisms involving $\alpha \mathrm{v} \beta 3$ receptor. Remarkably, NDAT (nanotetrac) blocked T4-mediated activation of PD-L1, providing a possibility for restoring immune defense against cancer cells. One of the key drawbacks of cancer therapies directed against PD-1/PDL-1 checkpoint, aimed at activation of immune responses, is the risk of autoimmune disease in treated patients. Since $\alpha v \beta 3$ is specifically overexpressed in cancer cells, and rarely functions on the surface of healthy cells, treatment of patients with NDAT would possibly not lead to autoimmune responses directed against noncancer cells (16). Clearly, the results of these promising in vitro studies require further validation in vivo on a larger group of cancer types.

\section{THYROID HORMONES AND RESPONSE TO THERAPY}

The results of several in vitro studies suggest that thyroid hormones may influence responses to chemotherapy. Through promotion of cancer cell proliferation, mitochondrial activity, and cell cycle progression from G0-G1 to S, T3 enhances the sensitivity of breast cancer cells to various chemotherapies $(22,23)$. In pancreatic cancer cells $\mathrm{T} 3$ treatment potentiated cytotoxic activities of chemotherapeutics such as cisplatin or gemcitabine (63). Contrasting observations were made for cell lines derived from colonic tumors. In colon cancer cells T3 increases the expression of P-gp (MDR1), one of the key mediators of xenobiotic efflux $(67,109)$. In contrast to the above mentioned prevalent non-genomic TH effects stimulating cancer progression, T3 activates $\mathrm{P}$-gp expression by TR binding to the direct repeat elements located upstream of the transcription start site of the P-gp gene (243). These results suggest that T3 may

\section{REFERENCES}

1. Ortiga-Carvalho TM, Chiamolera MI, Pazos-Moura CC, Wondisford FE. Hypothalamus-pituitary-thyroid axis. Compr Physiol. (2016) 6:1387-428. doi: $10.1002 /$ cphy.c150027

2. Piekiełko-Witkowska A, Nauman A. Iodothyronine deiodinases and cancer, J Endocrinol Invest. (2011) 34:716-28. doi: 10.3275/7754

3. Davis PJ, Goglia F, Leonard JL. Nongenomic actions of thyroid hormone. Nat Rev Endocrinol. (2016) 12:111-21. doi: 10.1038/nrendo.2015.205

4. Beatson GT. On the treatment of inoperable cases of carcinoma of the mamma: suggestions for a new method of treatment, with illustrative cases. Trans Med Chir Soc Edinb. (1896) 15:153-79.

5. Hercbergs A, Leith JT. Spontaneous remission of metastatic lung cancer following myxedema coma-an apoptosis-related phenomenon? J Natl Cancer Inst. (1993) 85:1342-3. doi: 10.1093/jnci/85.16.1342

6. Hercbergs AH, Ashur-Fabian O, Garfield D. Thyroid hormones and cancer: clinical studies of hypothyroidism in oncology. Curr Opin Endocrinol Diabetes Obes. (2010) 17:432-6. doi: 10.1097/MED.0b013e32833d9710 possibly interfere with drug treatments of colon cancer; however this hypothesis requires experimental verification. T4 and T3 also interfered with the activity of bortezomib, a key drug in treatment of MM patients (90).

\section{CONCLUSION}

The thyroid hormones are increasingly acknowledged for their tumor-promoting effects. We aimed in this review to shed light on this association in order to clarify which types of cancer are thyroid-hormone sensitive and therefore are expected to favorably respond to manipulation of the thyroid hormone axis. This is highly relevant, specifically in the context of the discovery of the T4 receptor site upon the $\alpha \mathrm{v} \beta 3$ integrin, which is overexpressed in many tumor cells and vasculature and may serve as an attractive target for inhibition. However, currently few T4- $\alpha v \beta 3$ inhibitors which demonstrated efficacy in several cancer types are under preclinical studies. Moreover, TH status is currently not yet considered as a risk factor or a prognostic factor in the clinical practice of cancer management, partly due to the conflicting data reported over the years. Future prospective studies to evaluate this link, with strict inclusion/exclusion criteria and predefined cut-off values, are therefore merited. Convincing results may promote the inclusion of thyroid status in the assessment of cancer patients and interventional studies may lead to novel treatment modalities that are desperately lacking in many aggressive cancers.

\section{AUTHOR CONTRIBUTIONS}

EK, AP-W, ME, and OA-F designed the review, collected the data, wrote, and approved the manuscript.

\section{SUPPLEMENTARY MATERIAL}

The Supplementary Material for this article can be found online at: https://www.frontiersin.org/articles/10.3389/fendo. 2019.00059/full\#supplementary-material
7. Moeller LC, Führer D. Thyroid hormone, thyroid hormone receptors, and cancer: a clinical perspective. Endocr Relat Cancer (2013) 20:R19-29. doi: 10.1530/ERC-12-0219

8. Freindorf M, Furlani TR, Kong J, Cody V, Davis FB, Davis PJ. Combined QM/MM study of thyroid and steroid hormone analogue interactions with $\alpha \mathrm{v} \beta 3$ integrin. J Biomed Biotechnol. (2012) 2012:959057. doi: 10.1155/2012/959057

9. Lin HY, Sun M, Tang HY, Lin C, Luidens MK, Mousa SA, et al. L-Thyroxine vs. 3,5,3'-triiodo-L-thyronine and cell proliferation: activation of mitogenactivated protein kinase and phosphatidylinositol 3-kinase. Am J Physiol Cell Physiol. (2009) 296:C980-91. doi: 10.1152/ajpcell.00305.2008

10. Burke RE, McGuire WL. Nuclear thyroid hormone receptors in a human breast cancer cell line. Cancer Res. (1978) 38(11 Pt 1):3769-73.

11. Hall LC, Salazar EP, Kane SR, Liu N. Effects of thyroid hormones on human breast cancer cell proliferation. J Steroid Biochem Mol Biol. (2008) 109:57-66. doi: 10.1016/j.jsbmb.2007.12.008

12. Dinda S, Sanchez A, Moudgil V. Estrogen-like effects of thyroid hormone on the regulation of tumor suppressor proteins, p53 and retinoblastoma, 
in breast cancer cells. Oncogene (2002) 21:761-8. doi: 10.1038/sj.onc.12 05136

13. Nogueira CR, Brentani MM. Triiodothyronine mimics the effects of estrogen in breast cancer cell lines. J Steroid Biochem Mol Biol. (1996) 59:271-9. doi: 10.1016/S0960-0760(96)00117-3

14. Tang HY, Lin HY, Zhang S, Davis FB, Davis PJ. Thyroid hormone causes mitogen-activated protein kinase-dependent phosphorylation of the nuclear estrogen receptor. Endocrinology (2004) 145:3265-72. doi: 10.1210/en.2004-0308

15. Flamini MI, Uzair ID, Pennacchio GE, Neira FJ, Mondaca JM, CuelloCarrión FD, et al. Thyroid hormone controls breast cancer cell movement via integrin $\alpha \mathrm{V} / \beta 3 / \mathrm{SRC} / \mathrm{FAK} / \mathrm{PI} 3-$ kinases. Horm Cancer (2017) 8:16-27. doi: $10.1007 / \mathrm{s} 12672-016-0280-3$

16. Lin HY, Chin YT, Nana AW, Shih YJ, Lai HY, Tang HY, et al. Actions of lthyroxine and Nano-diamino-tetrac (Nanotetrac) on PD-L1 in cancer cells. Steroids (2016) 114:59-67. doi: 10.1016/j.steroids.2016.05.006

17. Glinskii AB, Glinsky GV, Lin HY, Tang HY, Sun M, Davis FB, et al. Modification of survival pathway gene expression in human breast cancer cells by tetraiodothyroacetic acid (tetrac). Cell Cycle (2009) 8:3562-70. doi: 10.4161/cc.8.21.9963

18. Sar P, Peter R, Rath B, Das Mohapatra A, Mishra SK. 3, 3'5 Triiodo L thyronine induces apoptosis in human breast cancer MCF-7 cells, repressing SMP30 expression through negative thyroid response elements. PLoS ONE (2011) 6:e20861. doi: 10.1371/journal.pone.0020861

19. Martinez MB, Ruan M, Fitzpatrick LA. Altered response to thyroid hormones by prostate and breast cancer cells. Cancer Chemother Pharmacol. (2000) 45:93-102. doi: 10.1007/s002800050016

20. Cestari SH, Figueiredo NB, Conde SJ, Clara S, Katayama ML, Padovani $\mathrm{CR}$, et al. Influence of estradiol and triiodothyronine on breast cancer cell lines proliferation and expression of estrogen and thyroid hormone receptors. Arq Bras Endocrinol Metabol. (2009) 53:859-64. doi: 10.1590/S0004-27302009000700010

21. Martinez MB, Ruan M, Fitzpatrick LA. Altered response to thyroid hormones by breast and ovarian cancer cells. Anticancer Res. (2000) 20:4141-6.

22. Suhane S, Ramanujan VK. Thyroid hormone differentially modulates Warburg phenotype in breast cancer cells. Biochem Biophys Res Commun. (2011) 414:73-8. doi: 10.1016/j.bbrc.2011.09.024

23. Huang J, Jin L, Ji G, Xing L, Xu C, Xiong X, et al. Implication from thyroid function decreasing during chemotherapy in breast cancer patients: chemosensitization role of triiodothyronine. BMC Cancer (2013) 13:334. doi: 10.1186/1471-2407-13-334

24. Sellitti DF, Tseng YC, Latham KR. Effect of 3,5,3'-triiodo-L-thyronine on the incidence and growth kinetics of spontaneous mammary tumors in C3H/HeN mice. Cancer Res. (1981) 41(Pt. 1):5015-9.

25. Vermey ML, Marks GT, Baldridge MG. Effect of thyroid function on MNU-induced mammary carcinogenesis. Zool Sci. (2015) 32:272-7. doi: 10.2108/zs140124

26. Glushakov RI, Proshin SN, Tapil'skaya NI. The incidence of breast tumor during experimental hyperthyroidism. Bull Exp Biol Med. (2013) 156:245-7. doi: $10.1007 /$ s10517-013-2322-y

27. Vonderhaar BK, Greco AE. Effect of thyroid status on development of spontaneous mammary tumors in primiparous $\mathrm{C} 3 \mathrm{H}$ mice. Cancer Res. (1982) 42:4553-61.

28. Goodman AD, Hoekstra SJ, Marsh PS. Effects of hypothyroidism on the induction and growth of mammary cancer induced by 7,12dimethylbenz(a)anthracene in the rat. Cancer Res. (1980) 40:2336-42.

29. Macejova D, Radikova Z, Macho L, Liska J, Brtko J. MNU-induced carcinogenesis of rat mammary gland: effect of thyroid hormone on expression of retinoic acid receptors in tumours of mammary gland. Mol Cell Endocrinol. (2005) 244:47-56. doi: 10.1016/j.mce.2005.01.014

30. López-Fontana CM, Sasso CV, Maselli ME, Santiano FE, Semino SN, Cuello Carrión FD, et al. Experimental hypothyroidism increases apoptosis in dimethylbenzanthracene-induced mammary tumors. Oncol Rep. (2013) 30:1651-60. doi: 10.3892/or.2013.2648

31. Shoemaker JP, Bradley RL, Hoffman RV. Increased Survival and Inhibition of Mammary Tumors in Hypothyroid Mice. J Surg Res. (1976) 21:151-4. doi: 10.1016/0022-4804(76)90151-7
32. Martínez-Iglesias O, García-Silva S, Regadera J, Aranda A. Hypothyroidism enhances tumor invasiveness and metastasis development. PLOS ONE (2009) 4:e6428. doi: 10.1371/journal.pone.0006428

33. Shoemaker JP, Dagher RK. Remissions of mammary adenocarcinoma in hypothyroid mice given 5-fluorouracil and chloroquine phosphate. J Natl Cancer Inst. (1979) 62:1575-8.

34. Tsui KH, Hsieh WC, Lin MH, Chang PL, Juang HH. Triiodothyronine modulates cell proliferation of human prostatic carcinoma cells by downregulation of the B-cell translocation gene 2. Prostate (2008) 68:610-9. doi: $10.1002 /$ pros. 20725

35. Delgado-González E, Sánchez-Tusie AA, Morales G, Aceves C, Anguiano B. Triiodothyronine attenuates prostate cancer progression mediated by $\beta$-adrenergic stimulation. Mol Med. (2016) 22:1-11. doi: 10.2119/molmed.2015.00047

36. Zhang P, Chen L, Song Y, Li X, Sun Y, Xiao Y, et al. Tetraiodothyroacetic acid and transthyretin silencing inhibit pro-metastatic effect of L-thyroxin in anoikis-resistant prostate cancer cells through regulation of MAPK/ERK pathway. Exp Cell Res. (2016) 347:350-9. doi: 10.1016/j.yexcr.2016.08.019

37. Theodossiou C, Schwarzenberger P. Propylthiouracil reduces xenograft tumor growth in an athymic nude mouse prostate cancer model. Am J Med Sci. (2000) 319:96-9. doi: 10.1016/S0002-9629(15)40695-0

38. Theodossiou C, Skrepnik N, Robert EG, Prasad C, Axelrad TW, Schapira DV, et al. Propylthiouracil-induced hypothyroidism reduces xenograft tumor growth in athymic nude mice. Cancer (1999) 86:1596-601. doi: 10.1002/ (SICI) 1097-0142(19991015)86:8<1596::AID-CNCR30>3.0.CO;2-C

39. Meng R, Tang HY, Westfall J, London D, Cao JH, Mousa SA, et al. Crosstalk between integrin $\alpha v \beta 3$ and estrogen receptor- $\alpha$ is involved in thyroid hormone-induced proliferation in human lung carcinoma cells. PLoS ONE (2011) 6:e27547. doi: 10.1371/journal.pone.0027547

40. Mousa SA, Yalcin M, Bharali DJ, Meng R, Tang HY, Lin HY, et al. Tetraiodothyroacetic acid and its nanoformulation inhibit thyroid hormone stimulation of non-small cell lung cancer cells in vitro and its growth in xenografts. Lung Cancer (2012) 76:39-45. doi: 10.1016/j.lungcan.2011.10.003

41. Lin HY, Su YF, Hsieh MT, Lin S, Meng R, London D, et al. Nuclear monomeric integrin $\alpha \mathrm{v}$ in cancer cells is a coactivator regulated by thyroid hormone. FASEB J. (2013) 27:3209-16. doi: 10.1096/fj.12-2 27132

42. Kinoshita S, Sone S, Yamashita T, Tsubura E, Ogura T. Effects of experimental hyper- and hypothyroidism on natural defense activities against Lewis lung carcinoma and its spontaneous pulmonary metastases in C57BL/6 mice. Tokushima J Exp Med. (1991) 38:25-35.

43. Carmona-Cortés J, Rodríguez-Gómez I, Wangensteen R, Banegas I, GarcíaLora Á, Quesada A, et al. Effect of thyroid hormone-nitric oxide interaction on tumor growth, angiogenesis, and aminopeptidase activity in mice. Tumour Biol. (2014) 35:5519-26. doi: 10.1007/s13277-014-1726-2

44. Shinderman-Maman E, Cohen K, Weingarten C, Nabriski D, Twito $\mathrm{O}$, Baraf L, et al. The thyroid hormone- $\alpha \mathrm{v} \beta 3$ integrin axis in ovarian cancer: regulation of gene transcription and MAPK-dependent proliferation. Oncogene (2016) 35:1977-87. doi: 10.1038/onc.2015.262

45. Moriggi G, Verga Falzacappa C, Mangialardo C, Michienzi S, Stigliano A, Brunetti E, et al. Thyroid hormones (T3 and T4): dual effect on human cancer cell proliferation. Anticancer Res. (2011) 31:89-96.

46. Hsieh MT, Wang LM, Changou CA, Chin YT, Yang YSH, Lai HY, et al. Crosstalk between integrin $\alpha \mathrm{v} \beta 3$ and ER $\alpha$ contributes to thyroid hormoneinduced proliferation of ovarian cancer cells. Oncotarget (2017) 8:24237-49. doi: 10.18632/oncotarget.10757

47. Weingarten C, Jenudi Y, Tshuva RY, Moskovich D, Alfandari A, Hercbergs A, et al. The interplay between Epithelial-Mesenchymal Transition (EMT) and the thyroid hormones- $\alpha \mathrm{v} \beta 3$ axis in ovarian cancer. Horm Cancer (2018) 9:22-32. doi: 10.1007/s12672-017-0316-3

48. Shinderman-Maman E, Weingarten C, Moskovich D, Werner H, Hercbergs A, Davis PJ, et al. Molecular insights into the transcriptional regulatory role of thyroid hormones in ovarian cancer. Mol Carcinog. (2018) 57:97-105. doi: $10.1002 / \mathrm{mc} .22735$

49. Shinderman-Maman E, Cohen K, Moskovich D, Hercbergs A, Werner H, Davis PJ, et al. Thyroid hormones derivatives reduce proliferation and induce cell death and DNA damage in ovarian cancer. Sci Rep. (2017) 7:16475. doi: $10.1038 /$ s41598-017-16593-x 
50. Lin HY, Davis FB, Gordinier JK, Martino LJ, Davis PJ. Thyroid hormone induces activation of mitogen-activated protein kinase in cultured cells. Am J Physiol. (1999) 276(5 Pt 1):C1014-24. doi: 10.1152/ajpcell.1999.276.5.C1014

51. Lin HY, Shih A, Davis FB, Davis PJ. Thyroid hormone promotes the phosphorylation of STAT3 and potentiates the action of epidermal growth factor in cultured cells. Biochem J. (1999) 338(Pt 2):427-32.

52. Shih A, Zhang S, Cao HJ, Tang HY, Davis FB, Davis PJ, et al. Disparate effects of thyroid hormone on actions of epidermal growth factor and transforming growth factor-alpha are mediated by 3,5'-cyclic adenosine 5'-monophosphate-dependent protein kinase II. Endocrinology (2004) 145:1708-17. doi: 10.1210/en.2003-0742

53. Davis FB, Tang HY, Shih A, Keating T, Lansing L, Hercbergs A, et al. Acting via a cell surface receptor, thyroid hormone is a growth factor for glioma cells. Cancer Res. (2006) 66:7270-5. doi: 10.1158/0008-5472.CAN-05-4365

54. Lin HY, Tang HY, Keating T, Wu YH, Shih A, Hammond D, et al. Resveratrol is pro-apoptotic and thyroid hormone is anti-apoptotic in glioma cells: both actions are integrin and ERK mediated. Carcinogenesis (2008) 29:62-9. doi: 10.1093/carcin/bgm239

55. Liappas A, Alexandros L, Mourouzis I, Iordanis M, Zisakis A, Athanasios $\mathrm{Z}$, et al. Cell-type-dependent thyroid hormone effects on glioma tumor cell lines. J Thyroid Res. (2011) 2011:856050. doi: 10.4061/2011/856050

56. Sudha T, Bharali DJ, Sell S, Darwish NHE, Davis PJ, Mousa SA. Nanoparticulate tetrac inhibits growth and vascularity of glioblastoma xenografts. Horm Cancer (2017) 8:157-65. doi: 10.1007/s12672-017-0293-6

57. García-Silva S, Aranda A. The thyroid hormone receptor is a suppressor of ras-mediated transcription, proliferation, and transformation. Mol Cell Biol. (2004) 24:7514-23. doi: 10.1128/MCB.24.17.7514-7523.2004

58. Poplawski P, Nauman A. Thyroid hormone - triiodothyronine - has contrary effect on proliferation of human proximal tubules cell line (HK2) and renal cancer cell lines (Caki-2, Caki-1) - role of E2F4, E2F5 and p107, p130. Thyroid Res. (2008) 1:5. doi: 10.1186/1756-6614-1-5

59. Yalcin M, Bharali DJ, Lansing L, Dyskin E, Mousa SS, Hercbergs A, et al. Tetraidothyroacetic acid (tetrac) and tetrac nanoparticles inhibit growth of human renal cell carcinoma xenografts. Anticancer Res. (2009) 29:3825-31.

60. Liu R, Li Z, Bai S, Zhang H, Tang M, Lei Y, et al. Mechanism of cancer cell adaptation to metabolic stress: proteomics identification of a novel thyroid hormone-mediated gastric carcinogenic signaling pathway. Mol Cell Proteomics (2009) 8:70-85. doi: 10.1074/mcp.M800195-MCP200

61. Iishi H, Tatsuta M, Baba M, Yamamoto R, Taniguchi H. Enhancement by thyroxine of gastric carcinogenesis induced by $\mathrm{N}$-methyl-N'-nitroN-nitrosoguanidine in Wistar rats. $\mathrm{Br} J$ Cancer (1993) 68:515-8. doi: 10.1038/bjc. 1993.378

62. Sarosiek K, Gandhi AV, Saxena S, Kang CY, Chipitsyna GI, Yeo CJ, et al. Hypothyroidism in pancreatic cancer: role of exogenous thyroid hormone in tumor invasion-preliminary observations. J Thyroid Res. (2016) 2016:2454989. doi: 10.1155/2016/2454989

63. Michienzi S, Bucci B, Verga Falzacappa C, Patriarca V, Stigliano A, Panacchia L, et al. 3,3,5-Triiodo-L-thyronine inhibits ductal pancreatic adenocarcinoma proliferation improving the cytotoxic effect of chemotherapy. J Endocrinol. (2007) 193:209-23. doi: 10.1677/joe.1.07065

64. Yalcin M, Lin HY, Sudha T, Bharali DJ, Meng R, Tang HY, et al. Response of human pancreatic cancer cell xenografts to tetraiodothyroacetic acid nanoparticles. Horm Cancer (2013) 4:176-85. doi: 10.1007/s12672-013-0137-y

65. Rognoni JB, Pichard V, Honore S, Rigot V, Lehmann M, Roccabianca $M$, et al. Convergent effects of growth factors, hormones, and fibronectin are necessary for the enterocyte differentiation of a colon adenocarcinoma cell line (HT29-D4). Differentiation (1998) 63:305-17. doi: 10.1046/j.1432-0436.1998.6350305.x

66. Lee YS, Chin YT, Yang YSH, Wei PL, Wu HC, Shih A, et al. The combination of tetraiodothyroacetic acid and cetuximab inhibits cell proliferation in colorectal cancers with different K-ras status. Steroids (2016) 111:63-70. doi: 10.1016/j.steroids.2016.03.006

67. Mitin T, Von Moltke LL, Court MH, Greenblatt DJ. Levothyroxine upregulates P-glycoprotein independent of the pregnane $\mathrm{X}$ receptor. Drug Metab Dispos. (2004) 32:779-82. doi: 10.1124/dmd.32.8.779

68. Dentice M, Luongo C, Ambrosio R, Sibilio A, Casillo A, Iaccarino $\mathrm{A}$, et al. beta-Catenin regulates deiodinase levels and thyroid hormone signaling in colon cancer cells. Gastroenterology (2012) 143:1037-47. doi: 10.1053/j.gastro.2012.06.042

69. Iishi H, Tatsuta M, Baba M, Okuda S, Taniguchi H. Enhancement by thyroxine of experimental carcinogenesis induced in rat colon by azoxymethane. Int J Cancer (1992) 50:974-6. doi: 10.1002/ijc.2910500625

70. Chen RN, Huang YH, Lin YC, Yeh CT, Liang Y, Chen SL, et al. Thyroid hormone promotes cell invasion through activation of furin expression in human hepatoma cell lines. Endocrinology (2008) 149:3817-31. doi: 10.1210/en.2007-0989

71. Chung IH, Chen CY, Lin YH, Chi HC, Huang YH, Tai PJ, et al. Thyroid hormone-mediated regulation of lipocalin 2 through the Met/FAK pathway in liver cancer. Oncotarget (2015) 6:15050-64. doi: 10.18632/oncotarget.3670

72. Gnoni GV, Rochira A, Leone A, Damiano F, Marsigliante S, Siculella L. 3,5,3'triiodo-L-thyronine induces SREBP-1 expression by non-genomic actions in human HEP G2 cells. J Cell Physiol. (2012) 227:2388-97. doi: $10.1002 /$ jcp. 22974

73. Wang T, Xia L, Ma S, Qi X, Li Q, Xia Y, et al. Hepatocellular carcinoma: thyroid hormone promotes tumorigenicity through inducing cancer stemlike cell self-renewal. Sci Rep. (2016) 6:25183. doi: 10.1038/srep25183

74. Yen CC, Huang YH, Liao CY, Liao CJ, Cheng WL, Chen WJ, et al. Mediation of the inhibitory effect of thyroid hormone on proliferation of hepatoma cells by transforming growth factor-beta. J Mol Endocrinol. (2006) 36:9-21. doi: 10.1677/jme.1.01911

75. Lin $\mathrm{YH}$, Huang $\mathrm{YH}, \mathrm{Wu} \mathrm{MH}, \mathrm{Wu} \mathrm{SM}$, Chi HC, Liao CJ, et al. Thyroid hormone suppresses cell proliferation through endoglinmediated promotion of p21 stability. Oncogene (2013) 32:3904-14. doi: 10.1038/onc. 2013.5

76. Chung IH, Liu H, Lin YH, Chi HC, Huang YH, Yang CC, et al. ChIP-onchip analysis of thyroid hormone-regulated genes and their physiological significance. Oncotarget (2016) 7:22448-59. doi: 10.18632/oncotarget.7988

77. Chi HC, Liao CH, Huang YH, Wu SM, Tsai CY, Liao CJ, et al. Thyroid hormone receptor inhibits hepatoma cell migration through transcriptional activation of Dickkopf 4. Biochem Biophys Res Commun. (2013) 439:60-5. doi: 10.1016/j.bbrc.2013.08.028

78. Mishkin SY, Pollack R, Yalovsky MA, Morris HP, Mishkin S. Inhibition of local and metastatic hepatoma growth and prolongation of survival after induction of hypothyroidism. Cancer Res (1981) 41:3040-5.

79. Frau C, Loi R, Petrelli A, Perra A, Menegon S, Kowalik MA, et al. Local hypothyroidism favors the progression of preneoplastic lesions to hepatocellular carcinoma in rats. Hepatology (2015) 61:249-59. doi: 10.1002/hep.27399

80. Lin HY, Tang HY, Shih A, Keating T, Cao G, Davis PJ, et al. Thyroid hormone is a MAPK-dependent growth factor for thyroid cancer cells and is anti-apoptotic. Steroids (2007) 72:180-7. doi: 10.1016/j.steroids.2006.11.014

81. Lu C, Zhu X, Willingham MC, Cheng SY. Activation of tumor cell proliferation by thyroid hormone in a mouse model of follicular thyroid carcinoma. Oncogene (2012) 31:2007-16. doi: 10.1038/onc.2011.390

82. Yalcin M, Dyskin E, Lansing L, Bharali DJ, Mousa SS, Bridoux A, et al. Tetraiodothyroacetic acid (tetrac) and nanoparticulate tetrac arrest growth of medullary carcinoma of the thyroid. J Clin Endocrinol Metab. (2010) 95:1972-80. doi: 10.1210/jc.2009-1926

83. Yalcin M, Bharali DJ, Dyskin E, Dier E, Lansing L, Mousa SS, et al. Tetraiodothyroacetic acid and tetraiodothyroacetic acid nanoparticle effectively inhibit the growth of human follicular thyroid cell carcinoma. Thyroid (2010) 20:281-6. doi: 10.1089/thy.2009.0249

84. Fabian ID, Rosner M, Fabian I, Vishnevskia-Dai V, Zloto O, Shinderman Maman E, et al. Low thyroid hormone levels improve survival in murine model for ocular melanoma. Oncotarget (2015) 6:11038-46. doi: 10.18632/oncotarget.3566

85. Luongo C, Ambrosio R, Salzano S, Dlugosz AA, Missero C, Dentice M. The sonic hedgehog-induced type 3 deiodinase facilitates tumorigenesis of basal cell carcinoma by reducing Gli2 inactivation. Endocrinology (2014) 155:2077-88. doi: 10.1210/en.2013-2108

86. Ferreira E, da Silva AE, Serakides R, Gomes MG, Cassali GD. Ehrlich tumor as model to study artificial hyperthyroidism influence on breast cancer. Pathol Res Pract. (2007) 203:39-44. doi: 10.1016/j.prp.2006.09.005

87. Silva AE, Ferreira E, Ocarino NM, Moraes JR, Cassali GD, Serakides R. Effect of hypothyroidism on growth, viability and characteristics of ascitic Ehrlich 
tumor in ovariectomized and non-ovariectomized mice. J Appl Res. (2007) 7:158-66.

88. Kumar MS, Chiang T, Deodhar SD. Enhancing effect of thyroxine on tumor growth and metastases in syngeneic mouse tumor systems. Cancer Res. (1979) 39:3515-8.

89. Cohen K, Ellis M, Khoury S, Davis PJ, Hercbergs A, Ashur-Fabian O. Thyroid hormone is a MAPK-dependent growth factor for human myeloma cells acting via $\alpha v \beta 3$ integrin. Mol Cancer Res. (2011) 9:1385-94. doi: 10.1158/1541-7786.MCR-11-0187

90. Cohen K, Ellis M, Shinderman E, Khoury S, Davis PJ, Hercbergs A, et al. Relevance of the thyroid hormones- $\alpha \mathrm{v} \beta 3$ pathway in primary myeloma bone marrow cells and to bortezomib action. Leuk Lymphoma (2015) 56:1107-14. doi: 10.3109/10428194.2014.947612

91. Cohen K, Flint N, Shalev S, Erez D, Baharal T, Davis PJ, et al. Thyroid hormone regulates adhesion, migration and matrix metalloproteinase 9 activity via $\alpha v \beta 3$ integrin in myeloma cells. Oncotarget (2014) 5:6312-22. doi: 10.18632/oncotarget.2205

92. Cohen K, Abadi U, Hercbergs A, Davis PJ, Ellis M, Ashur-Fabian O. The induction of myeloma cell death and DNA damage by tetrac, a thyroid hormone derivative. Endocr Relat Cancer (2018) 25:21-34. doi: 10.1530/ERC-17-0246

93. Frick LR, Rapanelli M, Bussmann UA, Klecha AJ, Arcos ML, Genaro AM, et al. Involvement of thyroid hormones in the alterations of T-cell immunity and tumor progression induced by chronic stress. Biol Psychiatry (2009) 65:935-42. doi: 10.1016/j.biopsych.2008.12.013

94. Cayrol F, Díaz Flaqué MC, Fernando T, Yang SN, Sterle HA, Bolontrade $\mathrm{M}$, et al. Integrin $\alpha \mathrm{v} \beta 3$ acting as membrane receptor for thyroid hormones mediates angiogenesis in malignant T cells. Blood (2015) 125:841-51. doi: 10.1182/blood-2014-07-587337

95. Sterle HA, Barreiro Arcos ML, Valli E, Paulazo MA, Méndez Huergo SP, Blidner AG, et al. The thyroid status reprograms T cell lymphoma growth and modulates immune cell frequencies. J Mol Med. (2016) 94:417-29. doi: 10.1007/s00109-015-1363-2

96. Sterle HA, Valli E, Cayrol F, Paulazo MA, Martinel Lamas DJ, Diaz Flaqué MC, et al. Thyroid status modulates $\mathrm{T}$ lymphoma growth via cell cycle regulatory proteins and angiogenesis. J Endocrinol. (2014) 222:243-55.

97. Mousa SA, Davis FB, Mohamed S, Davis PJ, Feng X. Pro-angiogenesis action of thyroid hormone and analogs in a three-dimensional in vitro microvascular endothelial sprouting model. Int Angiol. (2006) 25:407-13.

98. Davis FB, Mousa SA, O'Connor L, Mohamed S, Lin HY, Cao HJ, et al. Proangiogenic action of thyroid hormone is fibroblast growth factordependent and is initiated at the cell surface. Circ Res. (2004) 94:1500-6. doi: 10.1161/01.RES.0000130784.90237.4a

99. Bergh JJ, Lin HY, Lansing L, Mohamed SN, Davis FB, Mousa S, et al. Integrin alphaVbeta3 contains a cell surface receptor site for thyroid hormone that is linked to activation of mitogen-activated protein kinase and induction of angiogenesis. Endocrinology (2005) 146:2864-71. doi: 10.1210/en.2005-0102

100. Mousa SA, O'Connor LJ, Bergh JJ, Davis FB, Scanlan TS, Davis PJ. The proangiogenic action of thyroid hormone analogue GC-1 is initiated at an integrin. J Cardiovasc Pharmacol. (2005) 46:356-60. doi: 10.1097/01.fjc.0000175438.94906.a0

101. Conde SJ, Luvizotto RA, Síbio MT, Katayama ML, Brentani MM, Nogueira CR. Tamoxifen inhibits transforming growth factor-alpha gene expression in human breast carcinoma samples treated with triiodothyronine. J Endocrinol Invest. (2008) 31:1047-51. doi: 10.1007/BF03345650

102. Pachucki J, Ambroziak M, Tanski Z, Luczak J, Nauman J, Nauman A. Type I 5'-iodothyronine deiodinase activity and mRNA are remarkably reduced in renal clear cell carcinoma. J Endocrinol Invest. (2001) 24:253-61. doi: 10.1007/BF03343855

103. Puzianowska-Kuznicka M, Nauman A, Madej A, Tanski Z, Cheng S, Nauman J. Expression of thyroid hormone receptors is disturbed in human renal clear cell carcinoma. Cancer Lett. (2000) 155:145-52. doi: 10.1016/S0304-3835(00)00416-X

104. Kamiya Y, Puzianowska-Kuznicka M, McPhie P, Nauman J, Cheng SY, Nauman A. Expression of mutant thyroid hormone nuclear receptors is associated with human renal clear cell carcinoma. Carcinogenesis (2002) 23:25-33. doi: 10.1093/carcin/23.1.25
105. Piekielko-Witkowska A, Master A, Wojcicka A, Boguslawska J, Brozda I, Tanski Z, et al. Disturbed expression of type 1 iodothyronine deiodinase splice variants in human renal cancer. Thyroid (2009) 19:1105-13. doi: $10.1089 /$ thy.2008.0284

106. Master A, Wójcicka A, Piekiełko-Witkowska A, Bogusławska J, Popławski $\mathrm{P}$, Tanski Z, et al. Untranslated regions of thyroid hormone receptor beta 1 mRNA are impaired in human clear cell renal cell carcinoma. Biochim Biophys Acta (2010) 1802:995-1005. doi: 10.1016/j.bbadis.2010.07.025

107. Le Cam L, Polanowska J, Fabbrizio E, Olivier M, Philips A, Ng Eaton E, et al. Timing of cyclin E gene expression depends on the regulated association of a bipartite repressor element with a novel E2F complex. EMBO J. (1999) 18:1878-90. doi: 10.1093/emboj/18.7.1878

108. Czarnecka AM, Matak D, Szymanski L, Czarnecka KH, Lewicki S, Zdanowski $\mathrm{R}$, et al. Triiodothyronine regulates cell growth and survival in renal cell cancer. Int J Oncol. (2016) 49:1666-78. doi: 10.3892/ijo.2016.3668

109. Nishio N, Katsura T, Inui K. Thyroid hormone regulates the expression and function of P-glycoprotein in Caco-2 cells. Pharm Res. (2008) 25:1037-42. doi: 10.1007/s11095-007-9495-x

110. Wu SM, Cheng WL, Lin CD, Lin KH. Thyroid hormone actions in liver cancer. Cell Mol Life Sci. (2013) 70:1915-36. doi: 10.1007/s00018-012-1146-7

111. Chan IH, Privalsky ML. Thyroid hormone receptor mutants implicated in human hepatocellular carcinoma display an altered target gene repertoire. Oncogene (2009) 28:4162-74. doi: 10.1038/onc.2009.265

112. Barreiro Arcos ML, Gorelik G, Klecha A, Genaro AM, Cremaschi GA. Thyroid hormones increase inducible nitric oxide synthase gene expression downstream from PKC-zeta in murine tumor T lymphocytes. Am J Physiol Cell Physiol. (2006) 291:C327-36. doi: 10.1152/ajpcell.00316.2005

113. Barreiro Arcos ML, Sterle HA, Paulazo MA, Valli E, Klecha AJ, Isse B, et al. Cooperative nongenomic and genomic actions on thyroid hormone mediated-modulation of $\mathrm{T}$ cell proliferation involve up-regulation of thyroid hormone receptor and inducible nitric oxide synthase expression. J Cell Physiol. (2011) 226:3208-18. doi: 10.1002/jcp.22681

114. Goemann IM, Romitti M, Meyer ELS, Wajner SM, Maia AL. Role of thyroid hormones in the neoplastic process: an overview. Endocr Relat Cancer (2017) 24:R367-85. doi: 10.1530/ERC-17-0192

115. Morris HP, Dubnik CS, Dalton AJ. Effect of prolonged ingestion of thiourea on mammary glands and the appearance of mammary tumors in adult $\mathrm{C} 3 \mathrm{H}$ mice. J Natl Cancer Inst. (1946) 7:159-69.

116. Dubnik CS, Morris HP, Dalton AJ. Inhibition of mammary-gland development and mammary-tumor formation in female $\mathrm{C} 3 \mathrm{H}$ mice following ingestion of thiouracil. J Natl Cancer Inst. (1950) 10:815-41.

117. Jull JW, Huggins C. Influence of hyperthyroidism and of thyroidectomy on induced mammary cancer. Nature (1960) 188:73. doi: 10.1038/188073a0

118. Martínez-Iglesias O, Garcia-Silva S, Tenbaum SP, Regadera J, Larcher F, Paramio JM, et al. Thyroid hormone receptor betal acts as a potent suppressor of tumor invasiveness and metastasis. Cancer Res. (2009) 69:5019. doi: 10.1158/0008-5472.CAN-08-2198

119. Liao CH, Yeh CT, Huang YH, Wu SM, Chi HC, Tsai MM, et al. Dickkopf 4 positively regulated by the thyroid hormone receptor suppresses cell invasion in human hepatoma cells. Hepatology (2012) 55:910-20. doi: 10.1002/hep. 24740

120. Grad B. The influence of hyper- and hypothyroidism on the incidence of lymphatic leukemia of AKR mice. Cancer Res. (1957) 17:266-71.

121. Morris DM, Wolff FF, Upton AC. The influence of the thyroid gland on the survival of rats and mice bearing transplanted lymphoid leukemia. Cancer Res. (1957) 17:325-8.

122. Morris DM. The effect of thyroidectomy and thyroid-stimulating hormone on a transplanted acute leukemia in the Fischer rat. Cancer Res. (1960) 20:373-6.

123. Sloviter HA. The effect of complete ablation of thyroid tissue by radioactive iodine on the survival of tumor-bearing mice. Cancer Res. (1951) 11:447-9.

124. Williams MW, Williams CS. Depression of growth of sarcoma 180 by hyperthyroidism. Cancer Chemother Rep. (1965) 45:1-4.

125. Di Girolamo D, Ambrosio R, De Stefano MA, Mancino G, Porcelli T, Luongo $\mathrm{C}$, et al. Reciprocal interplay between thyroid hormone and microRNA-21 regulates hedgehog pathway-driven skin tumorigenesis. J Clin Invest. (2016) 126:2308-20. doi: 10.1172/JCI84465 
126. Khan SR, Chaker L, Ruiter R, Aerts JG, Hofman A, Dehghan A, et al. Thyroid function and cancer risk: the rotterdam study. J Clin Endocrinol Metab. (2016) 101:5030-6. doi: 10.1210/jc.2016-2104

127. Tosovic A, Becker C, Bondeson AG, Bondeson L, Ericsson UB, Malm J, et al. Prospectively measured thyroid hormones and thyroid peroxidase antibodies in relation to breast cancer risk. Int J Cancer (2012) 131:2126-33. doi: $10.1002 /$ ijc. 27470

128. Brandt J, Borgquist S, Manjer J. Prospectively measured thyroid hormones and thyroid peroxidase antibodies in relation to risk of different breast cancer subgroups: a Malmö Diet and Cancer Study. Cancer Causes Control. (2015) 26:1093-104. doi: 10.1007/s10552-015-0602-8

129. Søgaard M, Farkas DK, Ehrenstein V, Jørgensen JO, Dekkers OM, Sørensen HT. Hypothyroidism and hyperthyroidism and breast cancer risk: a nationwide cohort study. Eur J Endocrinol. (2016) 174:409-14. doi: 10.1530/EJE-15-0989

130. Journy NMY, Bernier MO, Doody MM, Alexander BH, Linet MS, Kitahara CM. Hyperthyroidism, hypothyroidism, and cause-specific mortality in a large cohort of women. Thyroid (2017) 27:1001-10. doi: 10.1089/thy.2017.0063

131. Moossa AR, Evans DA, Brewer AC. Thyroid status and breast cancer. Reappraisal of an old relationship. Ann R Coll Surg Engl. (1973) 53:178-88.

132. Ditsch N, Liebhardt S, Von Koch F, Lenhard M, Vogeser M, Spitzweg C, et al. Thyroid function in breast cancer patients. Anticancer Res. (2010) 30:1713-7.

133. Saraiva PP, Figueiredo NB, Padovani CR, Brentani MM, Nogueira CR. Profile of thyroid hormones in breast cancer patients. Braz J Med Biol Res. (2005) 38:761-5. doi: 10.1590/S0100-879X20050005 00014

134. Ortega-Olvera C, Ulloa-Aguirre A, Ángeles-Llerenas A, Mainero-Ratchelous FE, González-Acevedo CE, Hernández-Blanco ML, et al. Thyroid hormones and breast cancer association according to menopausal status and body mass index. Breast Cancer Res. (2018) 20:94. doi: 10.1186/s13058-018-1017-8

135. Tosovic A, Bondeson AG, Bondeson L, Ericsson UB, Manjer J. T3 levels in relation to prognostic factors in breast cancer: a population-based prospective cohort study. BMC Cancer (2014) 14:536. doi: 10.1186/1471-2407-14-536

136. Tosovic A, Bondeson AG, Bondeson L, Ericsson UB, Malm J, Manjer J. Prospectively measured triiodothyronine levels are positively associated with breast cancer risk in postmenopausal women. Breast Cancer Res. (2010) 12:R33. doi: $10.1186 /$ bcr2587

137. Tseng FY, Lin WY, Li CI, Li TC, Lin CC, Huang KC. Subclinical hypothyroidism is associated with increased risk for cancer mortality in adult Taiwanese-a 10 years population-based cohort. PLoS ONE (2015) 10:e0122955. doi: 10.1371/journal.pone.0122955

138. Tosovic A, Bondeson AG, Bondeson L, Ericsson UB, Manjer J. Triiodothyronine levels in relation to mortality from breast cancer and all causes: a population-based prospective cohort study. Eur J Endocrinol. (2013) 168:483-90. doi: 10.1530/EJE-12-0564

139. Hardefeldt PJ, Eslick GD, Edirimanne S. Benign thyroid disease is associated with breast cancer: a meta-analysis. Breast Cancer Res Treat. (2012) 133:1169-77. doi: 10.1007/s10549-012-2019-3

140. Fang Y, Yao L, Sun J, Yang R, Chen Y, Tian J, et al. Does thyroid dysfunction increase the risk of breast cancer? A systematic review and meta-analysis. J Endocrinol Invest. (2017) 40:1035-47. doi: 10.1007/s40618-017-0679-x

141. Simon MS, Tang MT, Bernstein L, Norman SA, Weiss L, Burkman RT, et al. Do thyroid disorders increase the risk of breast cancer? Cancer Epidemiol Biomarkers Prev. (2002) 11:1574-8.

142. Cristofanilli M, Yamamura Y, Kau SW, Bevers T, Strom S, Patangan M, et al. Thyroid hormone and breast carcinoma. Primary hypothyroidism is associated with a reduced incidence of primary breast carcinoma. Cancer (2005) 103:1122-8. doi: 10.1002/cncr.20881

143. Brinton LA, Hoffman DA, Hoover R, Fraumeni JF. Relationship of thyroid disease and use of thyroid supplements to breast cancer risk. J Chronic Dis. (1984) 37:877-93. doi: 10.1016/0021-9681(84)90062-6

144. Cao J, Zhang J, Wang Z, Wang B, Lv F, Wang L, et al. Hypothyroidism as a potential biomarker of efficacy of famitinib, a novel VEGFR-2 inhibitor in metastatic breast cancer. Cancer Chemother Pharmacol. (2014) 74:389-98. doi: 10.1007/s00280-014-2505-x
145. Goldman MB, Monson RR, Maloof F. Benign thyroid diseases and the risk of death from breast cancer. Oncology (1992) 49:461-6. doi: 10.1159/000227093

146. Villa NM, Li N, Yeh MW, Hurvitz SA, Dawson NA, Leung AM. Serum thyrotropin concentrations are not predictive of aggressive breast cancer biology in euthyroid individuals. Endocr Pract. (2015) 21:1040-5. doi: 10.4158/EP15733.OR

147. Kuijpens JL, Nyklíctek I, Louwman MW, Weetman TA, Pop VJ, Coebergh JW. Hypothyroidism might be related to breast cancer in post-menopausal women. Thyroid (2005) 15:1253-9. doi: 10.1089/thy.2005.15.1253

148. Franceschi S, la Vecchia C, Negri E, Parazzini F, Boyle P. Breast cancer risk and history of selected medical conditions linked with female hormones. Eur J Cancer (1990) 26:781-5. doi: 10.1016/0277-5379(90)90151-I

149. Angelousi AG, Anagnostou VK, Stamatakos MK, Georgiopoulos GA, Kontzoglou KC. Mechanisms in endocrinology: primary HT and risk for breast cancer: a systematic review and meta-analysis. Eur J Endocrinol. (2012) 166:373-81. doi: 10.1530/EJE-11-0838

150. Kapdi CC, Wolfe JN. Breast cancer. Relationship to thyroid supplements for hypothyroidism. JAMA (1976) 236:1124-7. doi: 10.1001/jama.1976.03270110022020

151. Sandhu MK, Brezden-Masley C, Lipscombe LL, Zagorski B, Booth GL. Autoimmune hypothyroidism and breast cancer in the elderly. Breast Cancer Res Treat. (2009) 115:635-41. doi: 10.1007/s10549-008-0104-4

152. Hoffman DA, McConahey WM, Brinton LA, Fraumeni JF Jr. Breast cancer in hypothyroid women using thyroid supplements. JAMA (1984) 251:616-9. doi: 10.1001/jama.1984.03340290030015

153. Hellevik AI, Asvold BO, Bjøro T, Romundstad PR, Nilsen TI, Vatten LJ. Thyroid function and cancer risk: a prospective population study. Cancer Epidemiol Biomarkers Prev. (2009) 18:570-4. doi: 10.1158/1055-9965.EPI-08-0911

154. Chan YX, Knuiman MW, Divitini ML, Brown SJ, Walsh J, Yeap BB. Lower TSH and higher free thyroxine predict incidence of prostate but not breast, colorectal or lung cancer. Eur J Endocrinol. (2017) 177:297-308. doi: 10.1530/EJE-17-0197

155. Lehrer S, Diamond EJ, Bajwa AM, Kornreich R, Stagger S, Stone NN, et al. Association between serum triiodothyronine (t3) level and risk of disease recurrence in men with localized prostate cancer. Prostate Cancer Prostatic Dis. (2001) 4:232-4. doi: 10.1038/sj.pcan.4500542

156. Lehrer S, Diamond EJ, Stone NN, Droller MJ, Stock RG. Serum triiodothyronine is increased in men with prostate cancer and benign prostatic hyperplasia. J Urol. (2002) 168:2431-3. doi: 10.1016/S0022-5347(05)64161-4

157. Mondul AM, Weinstein SJ, Bosworth T, Remaley AT, Virtamo J, Albanes D. Circulating thyroxine, thyroid-stimulating hormone, and hypothyroid status and the risk of prostate cancer. PLoS ONE (2012) 7:e47730. doi: 10.1371/journal.pone.0047730

158. Mazzoccoli G, Pazienza V, Piepoli A, Muscarella LA, Giuliani F, Sothern RB. Alteration of hypothalamic-pituitary-thyroid axis function in nonsmall-cell lung cancer patients. Integr Cancer Ther. (2012) 11:327-36. doi: $10.1177 / 1534735411413269$

159. Hercbergs A, Mason J, Reddy C, Elson P. Thyroid hormones and lung cancer: primary hypothyroidism is prognostically significant for survival in lung cancer. Cancer Res. (2004). 1024.

160. Osorio JC, Ni A, Chaft JE, Pollina R, Kasler MK, Stephens D, et al. Antibody-mediated thyroid dysfunction during T-cell checkpoint blockade in patients with non-small-cell lung cancer. Ann Oncol. (2017) 28:583-9. doi: 10.1093/annonc/mdw640

161. Cornelli U, Belcaro G, Recchia M, Finco A. Levothyroxine and lung cancer in females: the importance of oxidative stress. Reprod Biol Endocrinol. (2013) 11:75. doi: 10.1186/1477-7827-11-75

162. Ness RB, Grisso JA, Cottreau C, Klapper J, Vergona R, Wheeler JE, et al. Factors related to inflammation of the ovarian epithelium and risk of ovarian cancer. Epidemiology (2000) 11:111-7. doi: 10.1097/00001648-200003000-00006

163. Minlikeeva AN, Freudenheim JL, Cannioto RA, Eng KH, Szender JB, Mayor $\mathrm{P}$, et al. History of thyroid disease and survival of ovarian cancer patients: results from the Ovarian Cancer Association Consortium, a brief report. $\mathrm{Br} \mathrm{J}$ Cancer (2017) 117:1063-9. doi: 10.1038/bjc.2017.267 
164. Rasool M, Naseer MI, Zaigham K, Malik A, Riaz N, Alam R, et al. Comparative study of alterations in Tri-iodothyronine (T3) and thyroxine (T4) hormone levels in breast and ovarian cancer. Pak J Med Sci. (2014) 30:1356-60. doi: 10.12669/pjms.306.5294

165. Goldman MB, Monson RR, Maloof F. Cancer mortality in women with thyroid disease. Cancer Res. (1990) 50:2283-9.

166. Seebacher V, Hofstetter G, Polterauer S, Reinthaller A, Grimm C, Schwameis $\mathrm{R}$, et al. Does thyroid-stimulating hormone influence the prognosis of patients with endometrial cancer? A multicentre trial. Br J Cancer (2013) 109:215-8. doi: 10.1038/bjc.2013.282

167. Mellemgaard A, From G, Jørgensen T, Johansen C, Olsen JH, Perrild H. Cancer risk in individuals with benign thyroid disorders. Thyroid (1998) 8:751-4. doi: 10.1089/thy.1998.8.751

168. Yung WK, Steward W, Marks JE, Griem ML, Mullan JF. Glioblastoma multiforme: treatment with radiation and triiodothyronine. Int J Radiat Oncol Biol Phys. (1976) 1:645-50. doi: 10.1016/0360-3016(76)90146-2

169. Ashur-Fabian O, Blumenthal DT, Bakon M, Nass D, Davis PJ, Hercbergs A. Long-term response in high-grade optic glioma treated with medically induced hypothyroidism and carboplatin: a case report and review of the literature. Anticancer Drugs (2013) 24:315-23. doi: 10.1097/CAD.0b013e32835c7a47

170. Hercbergs AA, Goyal LK, Suh JH, Lee S, Reddy CA, Cohen BH, et al. Propylthiouracil-induced chemical hypothyroidism with high-dose tamoxifen prolongs survival in recurrent high grade glioma: a phase I/II study. Anticancer Res. (2003) 23:617-26.

171. Bailey EB, Tantravahi SK, Poole A, Agarwal AM, Straubhar AM, Batten JA, et al. Correlation of degree of hypothyroidism with survival outcomes in patients with metastatic renal cell carcinoma receiving vascular endothelial growth factor receptor tyrosine kinase inhibitors. Clin Genitourin Cancer (2015) 13:e131-7. doi: 10.1016/j.clgc.2014.11.002

172. Kust D, Prpić M, Murgić J, Jazvić M, Jakšić B, Krilić D, et al. Hypothyroidism as a predictive clinical marker of better treatment response to sunitinib therapy. Anticancer Res. (2014) 34:3177-84.

173. Schmidinger M, Vogl UM, Bojic M, Lamm W, Heinzl H, Haitel A, et al. Hypothyroidism in patients with renal cell carcinoma: blessing or curse? Cancer (2011) 117:534-44. doi: 10.1002/cncr.25422

174. Riesenbeck LM, Bierer S, Hoffmeister I, Köpke T, Papavassilis P, Hertle L, et al. Hypothyroidism correlates with a better prognosis in metastatic renal cancer patients treated with sorafenib or sunitinib. World J Urol. (2011) 29:807-13. doi: 10.1007/s00345-010-0627-2

175. Baldazzi V, Tassi R, Lapini A, Santomaggio C, Carini M, Mazzanti R. The impact of sunitinib-induced hypothyroidism on progression-free survival of metastatic renal cancer patients: a prospective single-center study. Urol Oncol. (2012) 30:704-10. doi: 10.1016/j.urolonc.2010.07.015

176. Nearchou A, Valachis A, Lind P, Akre O, Sandström P. Acquired hypothyroidism as a predictive marker of outcome in patients with metastatic renal cell carcinoma treated with tyrosine kinase inhibitors: a literature-based meta-analysis. Clin Genitourin Cancer (2015) 13:280-6. doi: 10.1016/j.clgc.2014.10.002

177. Sella A, Hercbergs AH, Hanovich E, Kovel S. Does sunitinib-induced hypothyroidism play a role in the activity of sunitinib in metastatic renal cell carcinoma? Chemotherapy (2012) 58:200-5. doi: 10.1159/0003 37079

178. Shinohara N, Takahashi M, Kamishima T, Ikushima H, Otsuka N, Ishizu A, et al. The incidence and mechanism of sunitinib-induced thyroid atrophy in patients with metastatic renal cell carcinoma. Br J Cancer (2011) 104:241-7. doi: 10.1038/sj.bjc.6606029

179. Atkins MB, Mier JW, Parkinson DR, Gould JA, Berkman EM, Kaplan MM. Hypothyroidism after treatment with interleukin-2 and lymphokine-activated killer cells. N Engl J Med. (1988) 318:1557-63. doi: $10.1056 /$ NEJM198806163182401

180. Weijl NI, Van der Harst D, Brand A, Kooy Y, Van Luxemburg S, Schroder $J$, et al. Hypothyroidism during immunotherapy with interleukin-2 is associated with antithyroid antibodies and response to treatment. J Clin Oncol. (1993) 11:1376-83. doi: 10.1200/JCO.1993.11.7.1376

181. Turkyilmaz A, Eroglu A, Aydin Y, Yilmaz O, Karaoglanoglu N. A new risk factor in oesophageal cancer aetiology: hyperthyroidism. Acta Chir Belg. (2010) 110:533-6. doi: 10.1080/00015458.2010.11680671
182. Ko AH, Wang F, Holly EA. Pancreatic cancer and medical history in a population-based case-control study in the San Francisco Bay Area, California. Cancer Causes Control (2007) 18:809-19. doi: 10.1007/s10552-007-9024-6

183. Rodríguez-Molinero A, Hercbergs A, Sarrias M, Yuste A. Plasma 3,3'5Triiodo-L-thyronine [T3] level mirrors changes in tumor markers in two cases of metastatic cancer of the breast and pancreas treated with exogenous L-T3. Cancer Biomark. (2018) 21:433-8. doi: 10.3233/CBM-170668

184. Boursi B, Haynes K, Mamtani R, Yang YX. Thyroid dysfunction, thyroid hormone replacement and colorectal cancer risk. J Natl Cancer Inst. (2015) 107:djv084. doi: 10.1093/jnci/djv084

185. Mu G, Mu X, Xing H, Xu R, Sun G, Dong C, et al. Subclinical hypothyroidism as an independent risk factor for colorectal neoplasm. Clin Res Hepatol Gastroenterol. (2015) 39:261-6. doi: 10.1016/j.clinre.2014.08.002

186. Chan YX, Alfonso H, Chubb SA, Fegan PG, Hankey GJ, Golledge J, et al. Higher thyrotropin concentration is associated with increased incidence of colorectal cancer in older men. Clin Endocrinol. (2017) 86:278-85. doi: $10.1111 /$ cen.13271

187. Rennert G, Rennert HS, Pinchev M, Gruber SB. A case-control study of levothyroxine and the risk of colorectal cancer. J Natl Cancer Inst. (2010) 102:568-72. doi: 10.1093/jnci/djq042

188. Friedman GD, Schwalbe JS, Habel LA. Re: a case-control study of levothyroxine and the risk of colorectal cancer. J Natl Cancer Inst. (2011) 103:1637-9. doi: 10.1093/jnci/djr374

189. Schirripa M, Pasqualetti G, Giampieri R, Scartozzi M, Lonardi S, Rumanò L, et al. Prognostic value of thyroid hormone ratios in patients with advanced metastatic colorectal cancer treated with regorafenib: the TOREADOR study. Clin Colorectal Cancer (2018) 17:e601-15. doi: 10.1016/j.clcc.2018.05.013

190. Pinter M, Haupt L, Hucke F, Bota S, Bucsics T, Trauner M, et al. The impact of thyroid hormones on patients with hepatocellular carcinoma. PLoS ONE (2017) 12:e0181878. doi: 10.1371/journal.pone.0181878

191. Zhang Y, Chang Y, Ryu S, Cho J, Lee WY, Rhee EJ, et al. Thyroid hormones and mortality risk in euthyroid individuals: the Kangbuk Samsung health study. J Clin Endocrinol Metab. (2014) 99:2467-76. doi: 10.1210/jc.2013-3832

192. Hassan MM, Kaseb A, Li D, Patt YZ, Vauthey JN, Thomas MB, et al. Association between hypothyroidism and hepatocellular carcinoma: a case-control study in the United States. Hepatology (2009) 49:1563-70. doi: $10.1002 /$ hep. 22793

193. Reddy A, Dash C, Leerapun A, Mettler TA, Stadheim LM, Lazaridis KN, et al. Hypothyroidism: a possible risk factor for liver cancer in patients with no known underlying cause of liver disease. Clin Gastroenterol Hepatol. (2007) 5:118-23. doi: 10.1016/j.cgh.2006.07.011

194. Chu YD, Lin KH, Huang YH, Lin CC, Hung CF, Yeh TS, et al. A novel thyroid function index associated with opposite therapeutic outcomes in advanced hepatocellular carcinoma patients receiving chemotherapy or sorafenib. Asia Pac J Clin Oncol. (2018). doi: 10.1111/ajco.12983

195. Yeh NC, Chou CW, Weng SF, Yang CY, Yen FC, Lee SY, et al. Hyperthyroidism and thyroid cancer risk: a population-based cohort study. Exp Clin Endocrinol Diabetes (2013) 121:402-6. doi: 10.1055/s-0033-1341474

196. Nelson M, Hercbergs A, Rybicki L, Strome M. Association between development of hypothyroidism and improved survival in patients with head and neck cancer. Arch Otolaryngol Head Neck Surg. (2006) 132:1041-6. doi: 10.1001/archotol.132.10.1041

197. Smith GL, Smith BD, Garden AS, Rosenthal DI, Sherman SI, Morrison $\mathrm{WH}$, et al. Hypothyroidism in older patients with head and neck cancer after treatment with radiation: a population-based study. Head Neck (2009) 31:1031-8. doi: 10.1002/hed.21066

198. Patil VM, Noronha V, Joshi A, Bhattacharjee A, Goel A, Talreja V, et al. Influence of hypothyroidism after chemoradiation on outcomes in head and neck cancer. Clin Oncol. (2018) 30:675. doi: 10.1016/j.clon.2018.07.002

199. Ellerhorst JA, Cooksley CD, Grimm EA. Autoimmunity and hypothyroidism in patients with uveal melanoma. Melanoma Res. (2001) 11:633-7. doi: 10.1097/00008390-200112000-00010

200. Dalamaga M, Karmaniolas K, Papadavid E, Pelecanos N, Migdalis I. Association of thyroid disease and thyroid autoimmunity with multiple myeloma risk: a case-control study. Leuk Lymphoma (2008) 49:1545-52. doi: $10.1080 / 10428190802165946$ 
201. Ghalaut VS, Yadav S, Ghalaut PS, Yadav A, Sachdeva A, Yadav R, et al. Association of insulin like growth factor-1 (IGF-1) and thyroid hormones in patients of acute leukemia. Clin Lab. (2012) 58:227-31.

202. Moskowitz C, Dutcher JP, Wiernik PH. Association of thyroid disease with acute leukemia. Am J Hematol. (1992) 39:102-7. doi: 10.1002/ajh.2830390206

203. Dalamaga M, Lekka A, Karmaniolas K, Stathopoulou E, DionyssiouAsteriou A. Is thyroid autoimmunity a risk factor for developing primary myelodysplastic syndrome? Cancer Causes Control (2008) 19:371-8. doi: 10.1007/s10552-007-9096-3

204. Brandt F, Thvilum M, Almind D, Christensen K, Green A, Hegedüs L, et al. Graves' disease and toxic nodular goiter are both associated with increased mortality but differ with respect to the cause of death: a Danish populationbased register study. Thyroid (2013) 23:408-13. doi: 10.1089/thy.2012.0500

205. Ittermann T, Haring R, Sauer S, Wallaschofski H, Dörr M, Nauck M, et al. Decreased serum TSH levels are not associated with mortality in the adult northeast German population. Eur J Endocrinol. (2010) 162:579-85. doi: 10.1530/EJE-09-0566

206. Vadiveloo T, Donnan PT, Cochrane L, Leese GP. The Thyroid Epidemiology, Audit, and Research Study (TEARS): morbidity in patients with endogenous subclinical hyperthyroidism. J Clin Endocrinol Metab. (2011) 96:1344-51. doi: $10.1210 /$ jc. $2010-2693$

207. Metso S, Jaatinen P, Huhtala H, Auvinen A, Oksala H, Salmi J. Increased cardiovascular and cancer mortality after radioiodine treatment for hyperthyroidism. J Clin Endocrinol Metab. (2007) 92:2190-6. doi: 10.1210/jc.2006-2321

208. Lechner MG, Vyas CM, Hamnvik OR, Alexander EK, Larsen PR, Choueiri TK, et al. Hypothyroidism during tyrosine kinase inhibitor therapy is associated with longer survival in patients with advanced nonthyroidal cancers. Thyroid (2018) 28:445-53. doi: 10.1089/thy.20 17.0587

209. Hercbergs A. High tumor response rate to radiation therapy in biochemically hypothyroid patients. Proc Am Assoc Cancer Res. (1997) 248:1667.

210. Hercbergs A, Johnson RE, Ashur-Fabian O, Garfield DH, Davis PJ. Medically induced euthyroid hypothyroxinemia may extend survival in compassionate need cancer patients: an observational study. Oncologist (2015) 20:72-6. doi: 10.1634/theoncologist.2014-0308

211. Brandt J, Borgquist S, Almgren P, Försti A, Huss L, Melander O, et al. Thyroid-associated genetic polymorphisms in relation to breast cancer risk in the Malmö Diet and Cancer Study. Int J Cancer (2018) 142:1309-21. doi: $10.1002 /$ ijc. 31156

212. Hercbergs A, Mousa SA, Davis PJ. Nonthyroidal Illness Syndrome and Thyroid Hormone Actions at Integrin av $\beta 3$. J Clin Endocrinol Metab (2018) 103:1291-5. doi: 10.1210/jc.2017-01939

213. Kang JH, Kueck AS, Stevens R, Curhan G, De Vivo I, Rosner B, et al. A large cohort study of hypothyroidism and hyperthyroidism in relation to gynecologic cancers. Obstet Gynecol Int. (2013) 2013:743721. doi: $10.1155 / 2013 / 743721$

214. Brinton LA, Sakoda LC, Frederiksen K, Sherman ME, Kjaer SK, Graubard BI, et al. Relationships of uterine and ovarian tumors to pre-existing chronic conditions. Gynecol Oncol. (2007) 107:487-94. doi: 10.1016/j.ygyno.2007.08.002

215. Shih YL, Huang $\mathrm{YH}$, Lin $\mathrm{KH}$, Chu YD, Yeh CT. Identification of functional thyroid stimulating hormone receptor and TSHR gene mutations in hepatocellular carcinoma. Anticancer Res. (2018) 38:2793-802. doi: 10.21873/anticanres. 12523

216. Lechner MG, Vyas CM, Hamnvik OR, Alexander EK, Larsen PR, Choueiri TK, et al. Risk factors for new hypothyroidism during tyrosine kinase inhibitor therapy in advanced nonthyroidal cancer patients. Thyroid (2018) 28:437-44. doi: 10.1089/thy.2017.0579

217. Franklyn JA, Maisonneuve P, Sheppard M, Betteridge J, Boyle P. Cancer incidence and mortality after radioiodine treatment for hyperthyroidism: a population-based cohort study. Lancet (1999) 353:2111-5. doi: 10.1016/S0140-6736(98)12295-X

218. Humphrey LJ, Swedlow M. The relationship of breast disease to thyroid disease. Cancer (1964) 17:1170-3. doi: 10.1002/10970142(196409)17:9<1170::AID-CNCR2820170912>3.0.CO;2-R
219. Rini BI, Tamaskar I, Shaheen P, Salas R, Garcia J, Wood L, et al. Hypothyroidism in patients with metastatic renal cell carcinoma treated with sunitinib. J Natl Cancer Inst. (2007) 99:81-3. doi: 10.1093/jnci/djk008

220. Wolter P, Stefan C, Decallonne B, Dumez H, Bex M, Carmeliet P, et al. The clinical implications of sunitinib-induced hypothyroidism: a prospective evaluation. Br J Cancer (2008) 99:448-54. doi: 10.1038/sj.bjc.6604497

221. Sabatier R, Eymard JC, Walz J, Deville JL, Narbonne H, Boher $\mathrm{JM}$, et al. Could thyroid dysfunction influence outcome in sunitinibtreated metastatic renal cell carcinoma? Ann Oncol. (2012) 23:714-21. doi: $10.1093 /$ annonc/mdr275

222. Noronha V, Joshi A, Patil VM, Agarwal J, Ghosh-Laskar S, Budrukkar A, et al. Once-a-week versus once-every-3-weeks cisplatin chemoradiation for locally advanced head and neck cancer: a phase III randomized noninferiority trial. J Clin Oncol. (2018) 36:1064-72. doi: 10.1200/JCO.2017.74.9457

223. Jiskra J, Límanová Z, Barkmanová J, Smutek D, Friedmannová Z. Autoimmune thyroid diseases in women with breast cancer and colorectal cancer. Physiol Res. (2004) 53:693-702.

224. Giustarini E, Pinchera A, Fierabracci P, Roncella M, Fustaino L, Mammoli $\mathrm{C}$, et al. Thyroid autoimmunity in patients with malignant and benign breast diseases before surgery. Eur J Endocrinol. (2006) 154:645-9. doi: 10.1530/eje.1.02108

225. Syrigos KN, Konstantoulakis MM, Constantoulakis M, Marafelia P, Koutras D, Golematis BC. Thyroid autoantibodies and thyroid function in patients with gastric cancer. Acta Oncol. (1994) 33:905-7. doi: $10.3109 / 02841869409098454$

226. Fyssas I, Syrigos KN, Konstantoulakis MM, Tsibloulis V, Manouras A, Peveretos P, et al. Thyroid autoantibodies and thyroid function in patients with pancreatic adenocarcinoma. Acta Oncol. (1997) 36:65-8. doi: 10.3109/02841869709100735

227. Fiore E, Giustarini E, Mammoli C, Fragomeni F, Campani D, Muller I, et al. Favorable predictive value of thyroid autoimmunity in high aggressive breast cancer. J Endocrinol Invest. (2007) 30:734-8. doi: 10.1007/BF03350810

228. Farahati J, Roggenbuck D, Gilman E, Schütte M, Jagminaite E, Seyed Zakavi $\mathrm{R}$, et al. Anti-thyroid peroxidase antibodies are associated with the absence of distant metastases in patients with newly diagnosed breast cancer. Clin Chem Lab Med. (2012) 50:709-14. doi: 10.1515/CCLM.2011.819

229. Franzke A, Peest D, Probst-Kepper M, Buer J, Kirchner GI, Brabant G, et al. Autoimmunity resulting from cytokine treatment predicts long-term survival in patients with metastatic renal cell cancer. J Clin Oncol. (1999) 17:529-33. doi: 10.1200/JCO.1999.17.2.529

230. Tazebay UH, Wapnir IL, Levy O, Dohan O, Zuckier LS, Zhao QH, et al. The mammary gland iodide transporter is expressed during lactation and in breast cancer. Nat Med. (2000) 6:871-8. doi: 10.1038/78630

231. Ruf J, Toubert ME, Czarnocka B, Durand-Gorde JM, Ferrand M, Carayon P. Relationship between immunological structure and biochemical properties of human thyroid peroxidase. Endocrinology (1989) 125:1211-8. doi: 10.1210/endo-125-3-1211

232. Dişel U, Beşen A, Karadeniz C, Mertsoylu H, Sezer A, Köse F, et al. Prevalence of thyroid dysfunction in untreated cancer patients: a cross-sectional study. Med Oncol. (2012) 29:3608-13. doi: 10.1007/s12032-012-0254-4

233. Ratcliffe JG, Stack BH, Burt RW, Radcliffe WA, Spilg WG, Cuthbert J, et al. Thyroid function in lung cancer. Br Med J. (1978) 1:210-2. doi: 10.1136/bmj.1.6107.210

234. Cengiz SE, Cetinkaya E, Altin S, Gunluoglu Z, Demir A, Gunluoglu G, et al. Nutritional and prognostic significance of sick euthyroid syndrome in non-small cell lung cancer patients. Intern Med. (2008) 47:211-6. doi: 10.2169/internalmedicine.47.0423

235. Yasar ZA, Kirakli C, Yilmaz U, Ucar ZZ, Talay F. Can non-thyroid illness syndrome predict mortality in lung cancer patients? A prospective cohort study. Horm Cancer (2014) 5:240-6. doi: 10.1007/s12672-014-0183-0

236. Bunevicius A, Deltuva VP, Tamasauskas S, Smith T, Laws ER, Bunevicius $\mathrm{R}$, et al. Preoperative low tri-iodothyronine concentration is associated with worse health status and shorter five year survival of primary brain tumor patients. Oncotarget (2017) 8:8648-56. doi: 10.18632/oncotarget.14376

237. Hrycek A, Gruszka A. Thyroid hormone and insulin-like growth factor-I in patients with multiple myeloma treated with melphalan and prednisone. Arch Med Res. (2006) 37:74-8. doi: 10.1016/j.arcmed.2005.04.015 
238. Gao R, Chen RZ, Xia Y, Liang JH, Wang L, Zhu HY, et al. Low T3 syndrome as a predictor of poor prognosis in chronic lymphocytic leukemia. Int $J$ Cancer (2018) 143:466-77. doi: 10.1002/ijc.31327

239. Gao R, Liang JH, Wang L, Zhu HY, Wu W, Wu JZ, et al. Low T3 syndrome is a strong prognostic predictor in diffuse large B cell lymphoma. Br J Haematol. (2017) 177:95-105. doi: 10.1111/bjh.14528

240. Bunevicius A, Deltuva V, Tamasauskas S, Tamasauskas A, Laws ER, Bunevicius R. Low triiodothyronine syndrome as a predictor of poor outcomes in patients undergoing brain tumor surgery: a pilot study: clinical article. J Neurosurg. (2013) 118:1279-87. doi: 10.3171/2013.1.JNS121696

241. Hanahan D, Weinberg RA. Hallmarks of cancer: the next generation. Cell (2011) 144:646-74. doi: 10.1016/j.cell.2011.02.013

242. Hamanishi J, Mandai M, Matsumura N, Abiko K, Baba T, Konishi I. PD-1/PD-L1 blockade in cancer treatment: perspectives and issues. Int J Clin Oncol. (2016) 21:462-73. doi: 10.1007/s10147-0160959-z
243. Kurose K, Saeki M, Tohkin M, Hasegawa R. Thyroid hormone receptor mediates human MDR1 gene expression-Identification of the response region essential for gene expression. Arch Biochem Biophys. (2008) 474:82-90. doi: 10.1016/j.abb.2008.03.020

Conflict of Interest Statement: The authors declare that the research was conducted in the absence of any commercial or financial relationships that could be construed as a potential conflict of interest.

Copyright (๑) 2019 Krashin, Piekietko-Witkowska, Ellis and Ashur-Fabian. This is an open-access article distributed under the terms of the Creative Commons Attribution License (CC BY). The use, distribution or reproduction in other forums is permitted, provided the original author(s) and the copyright owner(s) are credited and that the original publication in this journal is cited, in accordance with accepted academic practice. No use, distribution or reproduction is permitted which does not comply with these terms. 